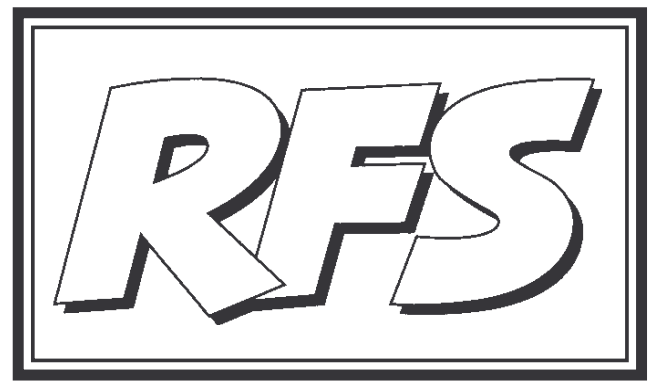

Revista de Fomento Social, 61 (2006), 519-560

\title{
Flexibilización del trabajo y precarización vital: el reto de la cohesión social
}

(PALABRAS ClaVE FLEXIBILIZACIÓN DEL tRABAJO, COHESIÓN SOCIAL, ESTADO DE BIENESTAR, VULNERABILIDAD, CAPITALISMO GLOBAL.

KEY WORDS: FLEXIBILITY AT WORK, SOCIAL COHESION, WELFARE STATE, VULNERABILITY, GLOBAL CAPITALISM)

Cuando el desempleo provoca pobreza, sabemos cómo enunciar el problema-lo típico es decir que «la economía no está creciendo a ritmo suficiente»-, y sabemos cuál es la solución liberal tradicional: "pleno empleo». Pero cuando tenemos pleno empleo, o casi pleno empleo, y hay trabajo disponible para cualquiera que lo busque y pueda

${ }^{1}$ Profesor de Sociología. Universidad del País Vasco / Euskal Herriko Unibertsitatea. Este texto fue presentado como ponencia para su discusión en la reunión del Grupo Fomento Social, celebrada en Madrid el 4 de noviembre de 2006. 
acceder a él, el problema se agrava y se reduce dentro de la maraña de expectativas que constituyen el "contrato social». [...] Nadie me dijo nunca que podías trabajar duro -incluso más duramente de lo que jamás hubieras imaginado- y encontrarte cada vez más hundido en la pobreza y el endeudamiento.

(BARBARA EHRENREICH)

\section{Los tiempos están cambiando}

Clifford Geertz es un destacado antropólogo norteamericano que ha publicado un hermoso texto en el que realiza algo así como una autobiografía profesional. $^{2}$ Su lectura nos ilustra a la perfección sobre los profundos cambios que las sociedades occidentales han experimentado en los últimos años, cam bios que complican sobremanera la tarea de la inserción laboral y, por ende, el objetivo de la cohesión social. Su relato autobiográfico empieza así:

He aprendido al menos una cosa en el proceso de improvisar una carrera académica: todo depende del momento exactoEntré en el mundo académico en la que había de ser la mejor época de todo el curso de su historia para ingresar en él: al menos en EE.UU. Cuando en 1946 salí de la Marina de EE. UU., una vez nos habíamos librado por muy poco de tener que invadir Japón gracias a la Bomba, en América se había puesto en marcha el boom de la educación superior y yo he surcado las olas, cresta tras cresta, hasta el día de hoy, cuando, al igual que yo, finalmente parecen decrecer.

El caso es que, tras participar en la guerra, Geertz recibió a sus veinte años, como millones de compatriotas, la G. I. Bill, una prestación que pre tendía recompensar a las tropas a su regreso de la guerra, financiando los estudios de los soldados. El impacto de esta prestación supuso la afluencia de dos millones y medio de veteranos a la universidad entre 1945 y 1950 , transformando radicalmente el escenario universitario y, después, el conjunto de la sociedad. Pues, aunque hoy nos parezca imposible, hubo un tiempo en que los Estados Unidos de América fueron muy distintos de los que hoy conocemos. En enero de 1941 el presidente de los Estados Unidos, Franklin D. Roosevelt, pronunció un famoso discurso, conocido como el "Discurso de las Cuatro Libertades", en el que decía:

No hay nada misterioso respecto de los cimientos de una democracia saludable y fuerte. Las cosas básicas esperadas por nuestro pueblo de sus sistemas político y económico son simples. Ellas son:

- La igualdad de oportunidad para los jóvenes y los demás.

- Un empleo para los que pueden trabajar.

- La seguridad (social) para los que la precisan.

2 C. GEERTZ (2002), Reflexiones antropológicas sobre temas filosóficos, Barcelona, Paidós. 
- El fin del privilegio especial para unos pocos.

- La preservación de las libertades civiles para todos.

- La participación en los frutos del progreso científico, en un estándar de vida cons tantemente creciente y ampliamente compartido.

Éstas son las cosas sencillas y básicas que nunca deberían perderse de vista en el tumulto y complejidad increíble de nuestro mundo moderno. La fuerza interior y du radera de nuestros sistemas económico y político depende del grado en que cumplen con estas expectativas.

La primera y fundamental ola, claramente providencial es ésta: de no haber sido por la G. I. Bill, Geertz -que creció en un ambiente rural durante la gran depresión- no hubiera llegado nunca a la universidad. Geertz no lo había previsto, pues no se lo esperaba, y cuenta que se pasó un verano vagabundeando por San Francisco, "reajustándose" a la vida civil a costa del gobierno. Su primera decisión, fue la de ser escritor -como Steinbeck o London- y para ello envió una solicitud de admisión para el Antioch College, una pequeña facultad de humanidades situada en una pequeña localidad de Ohio, experimental, inconformista y contracultural.

Eran otros tiempos, escribe Geertz. No tengo claro si por entonces sabía que estas solicitudes a veces se rechazan y yo no tenía un plan alternativo. Si me hubieran rechazado, probablemente me hubiera ido a trabajar a la compañía telefónica, hubiera intentado escribir por las noches, me habría olvidado de todo el asunto y todos nos hubiéramos ahorrado la situación en la que ahora estamos”.

Geertz fue admitido: segunda ola. Entonces accedió al mundo universitario sin tener nada claro.

Como quería ser escritor, pensé absurdamente, claro está, que debía especializarme en inglés. Pero incluso esto me pareció constrictor, de modo que viré a la filosofía, para cuyas exigencias cualquier clase a la que iba-musicología o política fiscal-podía virtualmente servirme. Por lo que respecta a la vertiente "práctica" del programa de "trabajo-estudio" y al preocupante interrogante que suscitaba-¿qué tipo de empresa comercial tiene un puesto vacante para un aprendiz de littérateur?- pensé , aún más absurdamente, que debía entrar en el periodismo como una ocupación que me facilitaría las cosas, algo que me respaldara hasta que encontrara mi propia voz; idea que pronto quedó aletargada tras un periodo de chico de los recados en la, tanto entonces como ahora, enloquecida y miserable redacción del New York Post. El resultado de todas estas búsquedas, pruebas y divagaciones (si bien, como ya dije, conseguí ingeniármelas para casarme en medio de todo aquello) fue que cuando llegué a graduarme, no tenía más idea de lo que hacer para ingresar en el mundo de la que había tenido cuando entré allí. Aún me estaba "reajustando».

Sólo pensemos en lo que diríamos hoy de un joven que pase por la uni versidad con esta actitud. Pensemos también lo que pensaríamos de una universidad que fomentase este tipo de formación, tan alejada de las exigen cias de "la práctica" y del mercado laboral. 
Tras su graduación se orientó hacia la antropología por consejo de un profesor. Coincidió que se acababa de instituir un programa experimental de becas e investigación para recién graduados. Uno de sus profesores, res ponsable de la concesión de las becas en Antioch, dio el visto bueno a su petición: "Me consideraba, dijo, no menos prometedor que cualquier otro, así que, si yo quería la beca, era mía. Con un estipendio tan inusualmente generoso para la época, de hecho, para cualquier época", suficiente para mantenerle a él y a su esposa durante dos años. Sin muchos planes -"Y una vez más, me subí a la ola"- se unió a un grupo que iba a hacer trabajo de campo en Java. "De la misma manera insospechada y casual en la que nos hicimos antropólogos, y casi con la misma inocencia, nos hicimos especialistas en Indonesia".

En fin: vuelve a Estados Unidos, se doctora, continua investigando en distintos centros universitarios, realiza trabajo de campo en Asia y África, "estudiando bazares, mezquitas, el cultivo del olivo, la poesía oral" y configurando, según sus palabras, "una carrera errática, mercurial, variada, libre, instructiva y nada mal pagada". Es entonces cuando se plantea una pregunta fundamental: "¿Es accesible hoy día una vida y una carrera como ésa?, ¿en la era de los adjuntos?, ¿cuando los estudiantes graduados se refieren a sí mismos como los "predesocupados»?". Su respuesta no puede ser más clarificadora:

Todo lo que sé es que hasta hace un par de años, de manera alegre y un tanto fatua, solía decirles a los estudiantes y a los colegas más jóvenes que me preguntaban cómo abrirse camino en una ocupación tan rara como la nuestra que se mantuvieran sin ataduras, que asumieran riesgos, que se resistieran al camino trillado, que evitaran hacer carrera, que hicieran su propio camino y que, sı procedían así, si se mantenían fieles a ese estilo, además de alertas, optimistas y leales a la verdad, según mi experiencia, podrían hacer lo que quisieran, lo que desearan, gozarían de una vida valiosa y, sin duda, próspera. Ya no doy esos consejos.

Ya no da esos consejos. ¿Por qué? Porque los tiempos han cambiado; per que nuestras sociedades han cambiado y porque hoy en día, probablemente, Geertz no hubiese podido coger todas esas olas.

\section{El trabajo ya no es lo que era}

El economista David Anisi inicia con estas palabras uno de sus libros, en los que somete a análisis crítico el desmontaje neoliberal del Estado de bienestar: 


\begin{abstract}
Debo comenzar recordándome a mí mismo, y también a ti lector occidental, que en el caso de que el que lea estas páginas tenga alrededor de veinte años su memoria personal sólo podrá referirse a tiempos de crisis. Este lector estará acostumbrado a convivir con el desempleo, con la marginación y la pobreza. Un trabajo fijo será para él una meta imposible, y probablemente ya habrá trabajado por cuenta ajena sin ningún tipo de contrato legal. Sabrá que conseguir una vivienda es algo que de momento no puede plantearse, y no se extrañará cuando vea como se privatiza la educación y la sanidad. Estará tan acostumbrado a los "vigilantes jurados» que no verá en ellos la privatización, también, de parte de lo que fue un importante servicio público. No se escandalizará cuando se hable de "flexibilizar el mercado de trabajo", puesto que él ya se encuentra suficientemente «flexibilizado» desde que tiene uso de razón. Y cuando oiga hablar de los problemas de las pensiones de jubilación le parecerá simplemente que el tema no va con él. No se escandalizará cuando se hable de «flexibilizar el mer cado de trabajo", puesto que él ya se encuentra suficientemente "flexibilizado» desde que tiene uso de razón. Y cuando oiga hablar de los problemas de las pensiones de jubilación le parecerá simplemente que el tema no va con él. Voy a tratar de contar aquí, a ese lector, que las cosas no fueron así siempre. ${ }^{3}$
\end{abstract}

En efecto, las cosas no fueron así siempre, ya que "a veces una época puede quedar resumida en una palabra clave que, como una marca de fábrica, indica sus aspectos y tendencias más llamativas o sus manías más persistentes, su retórica dominante". Así es. Cuando pensamos en la situa ción económica española y en sus consecuencias sociales, esa palabra sólo puede ser inseguridad, inseguridad o cualquiera de sus sinónimos de hecho, riesgo, incertidumbre, precariedad.

En nombre del progreso económico, en aplicación de los dictados de instituciones como la OCDE, ${ }^{5}$ en los últimos quince años hemos asistido al desmontaje sistemático de todo aquello (consensos e instituciones) que fundamentó los Estados de bienestar en Europa y que instituyó unas

3 D. AnISI (1995), Creadores de escasez. Del bienestar al miedo, Madrid, Alianza.

4 C. Magris (2001), Utopía y desencanto, Barcelona, Anagrama.

5 Ver, en particular, el documento Estudio de la OCDE sobre el empleo. Hechos, análisis, estrategias (1994), en el que tras caracterizar el paro como un problema de mala adaptación a un contexto económico que exige competir en un escenario de cambio permanente (ejemplo de naturalización de los procesos sociales), señala con meridiana claridad lo que hay que hacer y lo que no hay que hacer. Lo que no hay que hacer: ni repartir el trabajo por ley, ni adoptar medidas proteccionistas. Lo que hay que hacer. aumentar la flexibilidad del tiempo de trabajo; aumentar la flexibilidad de los costes salariales y de la mano de obra; revisar las disposiciones relativas a la seguridad en el empleo, que frenan su expansión en el sector privado; poner más el acento en las políticas activas de mercado de trabajo; mejorar las cualificaciones y las competencias de la mano de obra; revisar los sistemas de indemnización del paro y de prestaciones anejas, etc. 
políticas sociales caracterizadas por la construcción de "redes" o "mallas de seguridad" ( safety nets): un conjunto de medidas de asistencia social cuyo objetivo es garantizar un nivel mínimo de vida a aquellas personas en situación de exclusión que en la mayoría de los países desarrollados han adoptado la forma de políticas de ingresos mínimos. ${ }^{6}$ En la práctica, estas redes de protección social se constituían en "últimas redes", en el sentido de que estaban pensadas para entrar en acción cuando todo lo demás fallaba (ese "todo lo demás", en la práctica, se podía identificar con el empleo). Estaban ahí sólo para impedir que quienes caían del trapecio de la vida-casi siempre, cuando fallaba ese agarre social fundamental que es el empleo- se estrellaran irremediable y definitivamente contra el suelo. Se trataba, por tanto, de redes (instituciones y recursos) que cumplían una función paliativa: se activaban, por así decirlo, cuando el resbalón o la pérdida de agarre ya se habían producido.

Históricamente, esta concepción de la solidaridad social como red de seguridad se ha construido sobre cuatro presupuestos:

a) Pleno empleo. Se considera que todas las personas dispuestas a trabajar disponen o acabarán por encontrar un empleo estable y bien remune rado, por lo que la red de seguridad tan sólo ha de cumplir la función de "por si acaso".

b) Precariedad marginal o coyunturalAquellas personas caídas del trapecio del empleo son, en general, recuperables (reinsertables) o, en caso de no serlo, constituirán un número muy reducido.

c) Altruismo social. Allá donde, por la razón que sea, no llegue la iniciativa pública, cabe confiar en la presencia de iniciativas sociales (volunta riado) que tejen sus propias mallas de seguridad, más especializadas y locales que las públicas, pero con las mismas funciones.

d) Solidaridad familiar. Ésta ha sido la columna oculta del sistema de bienestar en las sociedades industriales avanzadas y su análisis en profundidad superaría los límites de este artículo. Por ello, me limito a suscribir lo dicho por Luis Moreno:

${ }^{6}$ L. Moreno (ed.) (2001), Pobreza y exclusión: la "malla de seguridad" en España Madrid, Consejo Superior de Investigaciones Científicas.

7 L. Moreno (2000), Ciudadanos precarios. La "última red" de protección socialBarcelona, Ariel, p. 14 . 
La familia es una institución esencial en la conformación de los regímenes del bienestar. Más allá de considerar sus recursos de bienestar como complementarios o de carácter «secundario» a la acción estatal, la familia ha sido por largo tiempo un soporte fundamental para la satisfacción vital de los ciudadanos, en particular en aquellas culturas y sociedades donde ha permanecido como órgano social primario de integración y reproducción sociales. ${ }^{8}$

Pero estos cuatro presupuestos de los sistemas de protección social, basados en las "mallas de seguridad", ya no se sostienen o, al menos, no lo hacen con la misma fuerza que antaño. Empezando por el final, la familia, es evidente que esta institución estabilizaba en la medida en que ella misma gozaba de estabilidad. Pero, ¿qué ocurre ahora? Existen nuevas formas de convivencia distintas de la familia nuclear patriarcal; se produce la disolución progresiva de la familia extensa, como consecuencia de la desterritorializa ción de las actividades, lo que acarrea dificultades prácticas para el ejercicio de la solidaridad intrafamiliar; aumenta la inseguridad económica, por las dificultades que sus miembros encuentran para incorporarse a o mantenerse en el mercado de trabajo; se "descargan" sobre las familias las consecuencias derivadas de las profundas transformaciones demográficas experimentadas por las sociedades desarrolladas, especialmente las que tienen que ver con el incremento de la esperanza de vida y la consiguiente extensión de enfermedades incapacitantes asociadas a la edad; e incluso se produce una obligada asunción por las familias de tareas de cuidado y atención externali zadas por unas instituciones sanitarias que aplican los mismos principios de gestión de la empresa privada (reducción de las estancias postoperatorias, etc.). Todo esto hace de las familias instituciones vulnerables. Recordemos tan sólo el dato ofrecido hace unos años por el departamento de estudios de Caixa Catalunya: uno de cada tres hogares españoles, exactamente el $34,2 \%$ del total, tiene como ingreso principal la pensión de un jubilado de 65 o más años; pongamos ahora este dato en relación con las propuestas de endurecer las condiciones para acceder a una pensión de jubilación digna y nos haremos una idea de lo que puede ocurrir en el futuro.

En cuanto al altruismo cívico, su indudable pujanza no puede llevarnos al error de hacer descansar en él la tarea de combatir los procesos de exclusión. No hay posibilidad ninguna de configurar una auténtica sociedad de bienestar, si tal sociedad es concebida como alternativa al Estado de bienestar. Dicho de otra forma, sin unas instituciones públicas comprometidas con el bienestar de todos, que, por tanto, pongan al servicio de la solidaridad

${ }^{8}$ L. MoReno, op. cit., pp. 118-119. 
recursos materiales y culturales, lo único que las organizaciones cívicas podrán hacer será, en el mejor de los casos, desarrollar unvoluntariado finsemanista: incluso aquellas personas que, a contrapelo de las orientaciones culturales dominantes, se sientan personalmente concernidas por el destino de sus conciudadanos, empezando por aquellos que son los sujetos más frágiles, habrán de dedicar la mayoría de su tiempo a velar por sus propios intereses de bienestar y estabilidad, permanentemente amenazados en un régimen de competencia desregulada, y sólo podrán dedicar "tiempos libres" al ejercicio de la solidaridad. De ahí el adjetivo de voluntariado o solidari dad finsemanista: durante cinco días a la semana nos veremos obligados a competir unos con otros en un espacio económico y laboral cada vez más selvático y durante dos días a la semana desarrollaremos iniciativas para construir una sociedad más justa y humana. No hace falta que diga cuál será el resultado de tal esfuerzo.

¿Y qué decir del empleo? El empleo es el principal -podríamos decir que único-mecanismo de inclusión en las sociedades de mercado. La inmensa mayoría de los ciudadanos somos lo que trabajamos; más aún, somqsorque trabajamos. De ahí el miedo que provoca la posibilidad de perder el empleo o, sencillamente, de no encontrarlo. Junto con el empleo no sólo se nos va la fuente socialmente normalizada para participar en la riqueza, sino que, cuando el paro entra por la puerta, la ciudadanía sale por la ventana. Pero si el derecho a la vida digna pasa por el derecho a trabajar, ¿qué ocurre cuándo millones de personas se ven imposibilitadas de cumplir con dicho deber no por su culpa, sino por razones estructurales?, ¿qué ocurre cuándo miles de personas se ven expuestas a la muerte por las condiciones de su trabajo?, y ¿qué ocurre cuando la competencia por el empleo no es ya fuente de autonomía sino mecanismo de humillación?

Porque ésta es la situación en la que nos encontramos. Las sociedades industriales avanzadas, unas sociedades que se han configurado históri camente como sociedades de trabajo, hoy son incapaces de ofrecer un empleo decente a todas aquellas personas que, en el ejercicio de un derecho fundamental, desean hacerlo. El mercado de trabajo es en la actualidad un enorme "juego de las sillas": todas y todos estamos llamados a participar en el juego, más que llamados, nos vemos forzados a ello; giramos y giramos en derredor de las sillas, mientras suena una alegre musiquilla confiando en poder sentarnos en una de las sillas cuando la música cese, pero sabiendo que no hay sillas para todos, por lo que alguien (¿tal vez nosotros mismos?) se quedará irremediablemente sin lugar para sentarse. No se trata de que 
quienes se quedan en pie sean necesariamente más torpes, o más vagos, o más viejos, o más indecisos, ni tampoco más tontos que los demás. Si en el juego de las sillas participaran todas las personas que subieron al podio de campeones en las pruebas de velocidad de los últimos juegos olímpicos, algunos se quedarían sin sitio. El problema es que no hay sillas para todas y cada una de las personas que participan en el juego. Más aún, el problema es que no puede haberlas.

El problema de la exclusión en las sociedades industriales avanzadas tiene que ver, fundamentalmente, con el hecho de que en el mercado de trabajo no hay empleos decentes suficientes para todas aquellas personas que quieren y pueden trabajar. Soy consciente de que lo que digo puede resultar chocante en unos momentos en los que el discurso oficial es el contrario. Un discurso que nos habla de pleno empleo y de necesidad de mano de obra inmigrante que cubra puestos de trabajo que, de otra manera, quedarían sin ser cubiertos.

\section{Del paro estructural al pleno empleo. ¿Para cuándo el empleo pleno?}

Hace apenas una decena de años el principal problema socioeconómico de las sociedades industriales avanzadas era el paro estructural. En 1994, la Organización para la Cooperación y el Desarrollo Económico dedicaba su Estudio de la OCDE sobre el empleo. Hechos, análisis, estrategias al análisis, diagnóstico y tratamiento de este fenómeno. ${ }^{9}$

Muy lejos quedaban los debates sobre el carácter del paro, sobre si éste era coyuntural o estructural, tan lejos como las tasas del 1,5\% y el 2,15\% existen tes en España entre los años 1960 y 1974 (1,7\% y 8\% si tenemos en cuenta el saldo migratorio acumulado). La evolución del empleo en España no dejaba lugar a dudas. Si distinguimos tres periodos de la economía española, en el primer tramo, entre 1977 y la crisis de 1985, el empleo disminuyó a un ritmo medio anual de 225.000 personas y la población activa aumentó a un ritmo de 65.000 personas, por lo que el paro aumentó en 290.000 personas al año; entre 1985 y la recuperación de 1991 el empleo creció alrededor de 302.000

9 El estudio original, que consta de dos volúmenes, lleva por título:Estudio de la OCDE sobre el empleo, Ministerio de Trabajo y Asuntos Sociales, Madrid 1996. Existe un resumen publicado por la propia OCDE (1994), Estudio de la OCDE sobre el empleo: hechos, análisis, estrategias, Madrid, Mundi-Prensa. Puede consultarse en: http://www.pdf.lacaixa.comunicacions.com/ ee/esp/ee01_inx_esp.pdf 
personas al año, pero la fuerte expansión de la población activa en ese mismo periodo amortiguó los efectos sobre el paro, que tan sólo disminuyó a razón de algo más de 94.000 personas al año; por último, durante la etapa de 1991 a la nueva crisis de 1993, un reducido incremento de la población activa no fue suficiente para compensar las fuertes reducciones de empleo, alrededor de 377.000 personas al año, con lo que el paro aumentó espectacularmente, a razón de 504.000 personas al año hasta alcanzar unas tasas cercanas al 24 por ciento de la población activa.

Este fortísimo deterioro del entorno laboral tuvo, como era de esperar, importantes consecuencias sobre la situación de los hogares, muchos de los cuales pasaron a engrosar el mundo de la denominadaueva pobreza, denominación bajo la que se incluían a aquellas personas y hogares anteriormente prósperos que, como consecuencia de la pérdida del empleo del cabeza de familia, entraban en un proceso creciente de vulnerabilidad y deterioro de sus condiciones de vida. ${ }^{10}$ Sólo la expansión registrada a partir de 1988 por el sistema no contributivo de garantía de rentas, con la incorporación al mismo de los ingresos mínimos de inserción, compensó relativamente la crisis del empleo.

En todo caso, más allá de las cifras existía un vivo debate académico sobre el futuro del empleo, expresión de un profundo temor al incremento o, cuan do menos, al mantenimiento de elevadas tasas de desempleo, cuyo ejemplo más destacado puede ser El fin del trabajo de Jeremy Rifkin, publicado en España en 1996. Los economistas se esforzaban por calcular, con la mayor exactitud posible, la "tasa natural de desempleo"11 correspondiente a cada una de las economías nacionales, mientras las organizaciones sindicales reivindicaban con energía el reparto del trabajo como la única estrategia coherente para combatir un paro estructural derivado de una oferta de empleos irremediablemente escasa.

10 Por aquellos años Cáritas publicó su famoso informe sobre la pobreza en España, descu briendo la cifra de 8 millones de personas pobres. EDIS (1984), "Pobreza y marginación": Documentación social. Por su parte, un estudio sobre la pobreza en Euskadi señalaba la cifra de 666.300 personas viviendo en situación de pobreza, un 31,5\% de la población total ( $L a$ pobreza en la Comunidad Autónoma Vasca, Vitoria-Gasteiz, Gobierno Vasco, 1987).

11 Concodia también como "tasa de paro que no aumenta la inflación”, denominada NAIRU en los textos de economía, acrónimo de Non-Accelerating Inflation Rate of Unemployment . El adjetivo de "natural" asociado al desempleo nos indica, bien a las claras, la característica dominante de la aproximación que en aquella época se hacía al desempleo: la convicción generalizada de que existía un límite infranqueable a la hora de reducir las tasas de paro. 
Sin embargo, casi de la noche a la mañana, con una rapidez y, sobre todo, una imprevisión similar a la que acompañó la caída del bloque soviético, para el año 2000 los datos y los discursos sobre el empleo y el paro habían dado un giro espectacular. Comenzando por los datos, a partir de 1994 el paro inició un progresivo descenso que llega hasta nuestros días, pasando de una tasa del 23,9\% hasta el aproximadamente $8 \%$ actual.

Europa ha recuperado el discurso del pleno empleo a partir de la cele bración del Consejo Europeo extraordinario que reunió, en marzo de 2000, a los dirigentes de todos los Estados de la Unión en Lisboa. Tanto es así que la Comisión Europea presentó en la cumbre de Lisboa una propuesta a los Estados miembros titulada Las políticas comunitarias al servicio del empleo en la que se planteaba su confianza en lograr el pleno empleo, es decir, unas tasas de paro entre el 4 y el 5\%, para el año 2010, siempre que el crecimiento medio de las economías europeas durante la próxima década fuese del $3 \%$.

Los enviados especiales del diario El País en la cumbre de Lisboa, Walter Oppenheimer y Sandro Pozzi, iniciaban así su información sobre el primer día de reunión:

El impresionante éxito de la economía norteamericana, que lleva ya ocho años seguidos creciendo a unas tasas de vértigo, está haciendo calar más que nunca el liberalismo económico. Europa intenta ahora ponerse a la misma altura de la mano de una nueva retórica, la que cambia las viejas apelaciones al Estado de bienestar por las más modernas de nueva economía, economía del conocimiento, o pura y simplemente, la más mágica de las palabras: Internet.

Los principales dirigentes europeos, con la excepción del francés Lionel Jospin, salieron de Lisboa más convencidos, si cabe, de las bondades de la liberalización económica. Después de Lisboa estaban tan convencidos que recuperaron un viejo objetivo, abandonado desde los años ochenta: el compromiso con el pleno empleo, que esperan alcanzar para el año 2010. ¿Por qué se recupera ahora un objetivo tradicionalmente vinculado a la socialdemocracia y orillado, de hecho, durante los años de la contrarreforma neoliberal? La respuesta es, en mi opinión, evidente: el pleno empleo del que se empieza a hablar ahora en Europa no es el mismo pleno empleo de los años 50 y 60; es el pleno empleo estadounidense, unpleno subempleo. Si aquél era a la vez consecuencia y causa de la capacidad de influencia de los ciudadanos y los trabajadores sobre las políticas públicas, este otro "pleno empleo" es consecuencia y será causa de su debilidad.

Sencillamente, recordemos cómo se define en la actualidad estadística mente la "ocupación". Para figurar en las encuestas como ocupado (y no, 
por tanto, como parado o inactivo), basta responder afirmativamente a la siguiente pregunta:

¿Realizó durante la semana pasada alguna actividad o trabajo remune rado por muy pequeño que éste fuera (al menos 1 hora en la semana) y de cualquier tipo (costura, clases particulares, etc.) incluso los considerados como chapuzas? ${ }^{12}$

Así pues, ¿de qué hablamos cuando hablamos hoy de "empleo"?

\section{De la estabilidad a la precariedad}

Durante las décadas de los 80 y de los 90 se han producido cambios fundamentales en la gestión empresarial de los recursos humanos, cambios que han tenido como consecuencia la modificación y, en algunos casos, la ruptura de la norma social de empleo que históricamente ha servido como elemento básico de integración social: un empleo estable y regulado, continuo y prolongado a lo largo de toda la vida activa hasta configurar una carrera profesional. En concreto, a lo largo del siglo XX pueden distinguirse claramente dos perspectivas normativas sobre el empleo cuya principal característica ha sido así resumida: si en la década de los sesenta la norma apuntaba a la estabilidad, en los años 90, la tendencia es hacia la precarización.

Paralelamente a la extensión de los sistemas de producciónust in time, la producción por encargo y sin caros almacenes de existencias, crece el con tingente de just in time workers, trabajadores que, como nuevos jornaleros, sólo acuden a las empresas por los limitados períodos de tiempo en que sean necesarios para responder a las exigencias de la producción al menor coste: unos meses, unas semanas, unos días, unas horas incluso. ${ }^{13}$

Salir del paro hoy no significa necesariamente salir del espacio de la precarización vital, más bien al contrario. El desempleo empieza a formar

12 Recogida textualmente (pregunta 120) del cuestionario para la elaboración de la Encuesta de Población en Relación con la Actividad (EPRA), con la que se estudia el mercado de trabajo en la Comunidad autónoma de Euskadi.

13 Como ejemplo puede servir la siguiente noticia, aparecida en El País, 22 de abril de 2006: "Seat propone un contrato temporal, vinculado a la vida de los modelos. El presidente de Seat, Andreas Schleef, calificó ayer de "restrictiva" la normativa laboral española y propuso la introducción de un nuevo contrato laboral temporal para el sector de la automoción cuya duración se vincule a la vida útil de los modelos, que oscila entre los cinco y los seis años. 
parte de una zona gris, de un territorio de vulnerabilidad laboral y vital, de manera que se sale del desempleo con relativa facilidad, pero sólo para volver a la misma situación al cabo de un tiempo, tras pasar por alguno o algunos de los empleos precarios que, de manera creciente, caracterizan la nueva norma social de empleo, instaurada a partir de los años 90 , que ha supuesto el paso de la estabilidad a la precarización.

De ahí que la Organización Internacional del Trabajo (OIT) considere imprescindible actualizar el concepto de pleno empleo, introduciendo en su caracterización elementos indicativos de lo que constituye un puesto de trabajo aceptable: un trabajo productivo en el que se protegen los derechos, lo cual significa que se perciben ingresos adecuados con una protección social apropiada. El Convenio núm. 122/1996 de la OIT hablaba de "pleno empleo productivo y libremente elegido, y no simplemente de pleno empleo. En 1999 la OIT profundizó en esta cuestión a través de una Memoria del Director General titulada, precisamente, Trabajo decente, en la que se afirma lo siguiente:

La OIT milita por un trabajo decente. No se trata simplemente de crear puestos de trabajo, sino que han de ser de una calidad aceptable. No cabe disociar la cantidad del empleo de su calidad. ${ }^{14}$

¿Por qué este énfasis en el contenido del empleo? Porque la OIT ha cons tatado que, durante toda la década de los años 90, una palabra clave ha sido inseguridad; no sólo en los países en desarrollo, donde la inmensa mayoría de la población ha vivido y vive en una situación crónica de inseguridad, pues también en los países desarrollados muchas personas viven preocupa das e inseguras de sus derechos en el trabajo y en la sociedad, sintiéndose expuestas a una evolución económica y social que parece haber escapado a su control, que Carnoy y Castells han caracterizado así en su informe para la OCDE sobre el futuro del trabajo, la familia y la sociedad en la "era de la información":

Lo que emerge de nuestro análisis es la visión de una economía extraordinariamente dinámica, flexible y productiva, junto con una sociedad inestable y frágil, y una cre ciente inseguridad individual. ${ }^{15}$

14 Memoria del Director general, Trabajo decente, OIT, Ginebra 1999. Puede ser consultada en el sitio Internet de la OIT, http://www.ilo.org/public/spanish/10ilc/ilc87/reports.htm.

15 M. Carnoy y M. Castells (1997), Sustainable Flexibility. A Prospective Study on Work, Family and Society in the Information Age, Paris, OECD. 
De ahí que en la literatura sociológica se hable de la "sudafricanización"16 o de la "brasileñización de occidente" 17; por su parte, Gallino concluye su análisis sobre la informalizaci ón del trabajo en los pa íses desarrollados afirmando que lasurización del Norte parece estar avanzando. ${ }^{18}$ Lo precario, lo discontinuo, lo informal, características todas ellas del llamado tercer mundo, están irrumpiendo en el mundo occidental. En el marco de una cre ciente economía política de la inseguridad, "la inseguridad endémica será el rasgo distintivo que caracterice en el futuro el modo de vida de la mayoría de los humanos" (Beck).

¿Puede alguien extrañarse entonces de que cada vez proliferen más en nuestras sociedades los pobres con trabajo : personas ocupadas, sí, pero en unas condiciones que no les permite superar el umbral de la exclusión, característicos del modelo laboral estadounidense (working poors) y, hasta hace relativamente poco, inconcebibles en Europa, donde estar ocupado y ser pobre era una contradicción. ${ }^{19}$ Este fenómeno indica que la otrora clara frontera entre trabajo y exclusión se ha convertido en una frontera porosa: hoy es posible trabajar y, al tiempo, encontrarse en situación de exclusión leve o moderada.

No tan publicitado como elcow boy o elmarine, sin embargo puede que el trabajador pobre represente mejor que ningún otro personaje al americano de a pie. Ha sido el protagonista de toda una larga serie de grandes obras literarias. Desde El talón de hierro de Jack London o La jungla de Upton Sin-

16 A. Gorz (1995), Metamorfosis del trabajo, Madrid, Sistema.

17 U. BEcK (2000), Un nuevo mundo feliz, Barcelona, Paidós.

18 L. Galuino (2002), "La informalización del trabajo en los países desarrollados”Sociología del Trabajo, no 45 (primavera).

19 Es ésta una cuestión que está muy presente en la reflexión y en el análisis del mercado de trabajo en Estados Unidos; cfr. MUunger (2002) Laboring Below the Line.The New Ethnography of Poverty, Low-Wage Work, and Survival in the Global EconomyRussell Sage Foundation; B. EHRENREICH (2003),Por cuatro duros. COmo (no) apãárselas en Estados Unidos Barcelona, RBA; D. K. SHIPLER (2004), The Working Poor: Invisible in America Alfred A. Knopf. Esta temática no ha sido suficientemente asumida por el pensamiento social europeo en general, ni mucho menos en el español. Aún así, empezamos a contar con datos y análisis al respecto como los siguientes: European Industrial Relations Observatory (2002), Low-wage workers and the "working poor" : http://www.eirofound.ie/2002/08/study/TN0208101S.htm l; European Foundation for the Improvement of Living and Working Conditions, Working poor in the European Union, Office for Official Publications of the European Communities: http://www. eurofound.eu.int; y L. BARNONE and A. C. GUIO, In-Work Poverty, Eurostat: http://epp.eurostat. cec.eu.int/cache/ITY_OFFPUB/KS-NK-05-005-EN.PDF. 
clair, escritas en la primera década del siglo, pasando por obras de los años 30, 40 y 50 como El camino del tabaco de Erskine Caldwell, Elogiemos ahora a hombres famosos de James Agee y Walker Evans, En lucha incierta y Las uvas de la ira de John Steinbeck, o Muerte de un viajante de Arthur Millar, llegamos en nuestros días a las novelas y relatos de autores como Raymond Carver, Richard Ford o Cormac McCarthy, por citar sólo unos pocos. ${ }^{20}$

Ésta es la descripción que hace Alan Wolfe de los trabajadores en Nor teamérica:

En la actualidad, los hombres ya no están sindicados, ya no trabajan en una fábrica y ya no están bien pagados, mientras sus mujeres trabajan también (probablemente en el sector servicios), ganan justo lo suficiente para llegar a duras penas a levantar la renta familiar al nivel en que se encontraba, en dólares constantes, hace veinticinco años. $^{21}$

El trabajador norteamericano aludido vive para trabajar, porque su empleo es tan precario o tan mal pagado que no le permite trabajar para vivir con dignidad; dos o más empleos se acumulan para poder salir adelante; son frecuentes los cambios de empresa, muchas veces obligándole a cambiar de ciudad e incluso de Estado. Este trabajador, desorganizado, sin derechos, lucha en solitario por salir adelante en un entorno ferozmente competitivo; es el trabajador que ocultan las grandes magnitudes económicas: ¿es el trabajador en el que quieren convertirnos?

Según datos ofrecidos por la Conferencia de Obispos Católicos de Estados Unidos en su informe Poverty USA: El estado de la pobreza en los EEUU , ${ }^{22}$ desde el 2000 el número absoluto de estadounidenses en la pobreza creció en 3 millones de personas. La proporción oficial de personas en la pobreza en 2002, el año más reciente del que tenemos estos datos, fue del 12,1\%, por encima del 11,7\% del 2001. El número total de estadounidenses por debajo del umbral de la pobreza era de 34,6 millones, 1,7 millones más que en 2001 cuando hubo 32,9 millones de personas en la pobreza. Como media, uno de cada tres estadounidenses (34,2\% de entre todas las personas en los

20 Tampoco el cine ha sido ajeno a esta figura. Además de películas clásicas basadas en algunas de las obras citadas, comoLas uvas de la irade John Ford (1940), podemos no sólo recordar sino volver a ver pélículas más recientes como las del director John Sayles o la más comercial John Q, protagonizada por Denzel Washington.

21 A. Wolfe (1992), "La vida americana o el triunfo de la ambivalencia".Debats, nº 41 (septiembre), p. 6.

22 http://www.usccb.org/cchd/povertyusa/spanish/povfacts.php 
EE.UU.), ha sido clasificado como persona que vive debajo del umbral de la pobreza, al menos dos meses al año. El número de estadounidenses que viven en pobreza extrema (aquellos cuyos ingresos no llegan ni a la mitad de los especificados como umbral de la pobreza) aumentó en 600.000 personas en 2002, llegando a 14,1 millones.

Los niños en los EE. UU. sufren la mayor proporción de la pobreza, en particular los menores de 6 años. El número absoluto de niños viviendo en pobreza ha crecido de 11,7 millones en 2001 a 12,1 millones en 2002. En 2002, la tasa de niños en pobreza menores de 6 años era del 18,5\%, aproximada mente uno de cada cinco niños. De los niños menores de seis años que viven en hogares encabezados sólo por una mujer -sin presencia de varón- casi la mitad (48,6\%) estaba sumido en la pobreza, cinco veces más niños que en familias encabezadas por una pareja casada.

Y, ¿qué ocurre con los trabajadores, objeto fundamental de nuestra re flexión? Según el mismo informe, uno de cada tres estadounidenses que viven en la pobreza mantuvo un trabajo a lo largo de 2002 (el 37,9 por ciento, es decir, 9 millones de personas). Aun así, estas personas no pudieron ganar suficiente dinero para poder pagar por sus necesidades básicas: casa, co mida y salud. De entre todos los estadounidenses que viven y trabajan en la pobreza, 2,6 millones (el 11,2\%) mantienen un trabajo a tiempo completo, pero ganan un salario tan bajo que a pesar de sus esfuerzos viven bajo el umbral de la pobreza.

Además, en contra del mito que difunden las corporaciones estadouni denses, la mayoría de los trabajadores que reciben el salario mínimo no son adolescentes que trabajan para ganar un poco de dinero al salir de la escuela. Son hombres y mujeres que tratan de mantener a sus familias. De acuerdo con un informe del Instituto de Política Económica (EPI), titulado No es posible llegar a fin de mes: el aumento del salario mínimo es desde hace tiempo necesario, si el salario mínimo se incrementara hasta unos modestos 7 dólares por hora, el $72 \%$ de todos los beneficiados (unos 7,4 millones de trabajadores) sería mayor de 20 años. De estos, el $44 \%$ trabaja a tiempo completo (al menos 35 horas a la semana) y el $36 \%$ de las familias con alguien que recibiera el aumento depende exclusivamente del salario de esa persona. Las mujeres serían el $64 \%$ de las personas beneficiadas por el aumento y las minorías son, de hecho, los grupos más afectados por el salario mínimo. Mientras los trabajadores afro-americanos suponen sólo el $11 \%$ de la fuerza laboral, estos constituirían el 15\% de las personas afectadas 
por un incremento del salario mínimo. Los hispanos son el 13\% de la fuerza laboral, pero serían el 19\% de los beneficiados por cualquier subida.

El último aumento del salario mínimo se produjo en 1997, cuando se su bió de 4,75 a 5,15 dólares por hora, a lo largo de dos años. Al no tenerse en cuenta la inflación, el salario mínimo ha ido perdiendo valor adquisitivo año tras año. De esta manera, en las últimas décadas, la distancia entre el salario mínimo y el salario promedio por hora devengado por los trabajadores se ha convertido en un abismo enorme. En los años 50 y 60 el salario mínimo federal equivalía al 50\% del salario promedio. En los años 70 era sólo el 44\%, y entre los 80 y 90 bajó al 39\%; hoy la cifra es 33\%.

En su libroNickel and Dimed-publicado en castellano con el título dePor cuatro duros-, la periodista Barbara Ehrenrich nos ofrece una excepcional y vivísima descripción de lo que significa trabajar en Estados Unidos a cambio de salarios miserables. Su dramática situación queda perfectamente reflejada en las líneas siguientes:

\begin{abstract}
Mucha gente gana bastante menos de lo que necesita para vivir. ¿Cuánto es lo que se necesita? El Economic Policy Institute revisó hace poco docenas de estudios sobre lo que constituye el «salario mínimo» y llegó a la cifra promedio de 30.000 dólares anuales para una familia de un adulto con dos niños, que significa un salario de 14 dólares la hora. Ése no es exactamente el mínimo con el cual puede vivir una familia de ese tipo. El cálculo incluye seguro de salud, teléfono, guardería en un centro autorizado, que está muy lejos del alcance de millones de personas. Pero no incluye comidas en restaurantes, alquiler de vídeos, acceso a Internet, vino y licores, cigarrillos, billetes de lotería, ni siquiera demasiada carne. Lo chocante es que la mayoría de los trabajado res estadounidenses -alrededor del 60 por ciento-gana menos de 14 dólares la hora. Muchos de ellos se las apañan formando equipo con otro asalariado, el cónyuge o un hijo crecido. Algunos recurren a la ayuda estatal, en forma de bonos para alimentos, vales para alojamiento, créditos para el pago de impuesto de las ganancias o-para aquellos que cuentan con la asistencia social de estados relativamente generosos- sub sidios para la atención a los niños. Pero otros -por ejemplo, las madres solteras- no disponen más que de sus salarios para mantenerse, no importa cuántas sean las bocas que deban alimentar. ${ }^{23}$
\end{abstract}

El destacado economista Paul Krugman publicaba enThe New York Times el 20 de octubre de 2002 un largo artículo titulado “The Class Wars" en el que, tras afirmar argumentadamente que los Estados Unidos han vuelto a las desigualdades de los años veinte en la distribución de la riqueza, ${ }^{24}$ advierte

23 B. Ehrenreich, Por cuatro duros. Cómo (no) apañárselas en Estados Unidos, RBA Libros, Barcelona 2003, pp. 228-229.

24 En una conferencia en España sostenía que tal afirmación podía generalizarse al conjunto 
del riesgo de que la democracia sufra, por esta razón, de una grave pérdida de calidad, hasta convertirse, en la práctica, en poco más que un régimen plutocrático:

Es fácil imaginar que podemos convertirnos en un país en el que las grandes recompensas están reservadas para quienes tienen las conexiones adecuadas; en el que la gente corriente tiene escasas expectativas de progreso; en el que el compromiso político carece de sentido, porque al final son los intereses de la elite los que resultan satisfechos.

Pero, si bien puede ser uno de esos hechos típicamente americanos, el de los working poors no es, de ninguna manera, exclusivo de ese país. Según un informe de Eurostat un 7\% de la población empleada en la UE-25 alrededor de 14 millones de trabajadores (11 millones en la UE-15), vivían en 2001 en un hogar cuya renta equivalente se situaba por debajo del umbral de pobreza. Teniendo en cuenta a la totalidad de los miembros del hogar viviendo con esos trabajadores pobres, 20 millones de personas se encontraban afectadas por la in-work poverty en la Europa de los 15, el 6\% de toda la población y el 36\% de la población en riesgo de pobreza.

El carácter falaz de estas políticas de la inseguridad queda evidenciado por el hecho de que, si bien en los últimos quince años las tasas de paro se han reducido significativamente, la tasa de pobreza se mantiene o, incluso, se ha incrementado: si en 1984 un ya clásico estudio promovido por Cáritas Española descubría la infamante realidad de ocho millones de pobres, en el año 2000 un nuevo estudio nos revela la consistencia de la pobreza en la sociedad española: más de dos millones de familias, unos ocho millones y medio de personas, viven bajo el umbral de la pobreza. ${ }^{26}$

de las sociedades desarrolladas El País, 23-5-03). Krugman presenta algunos datos contun dentes: "En 1970 el máximo responsable de una empresa cobraba 40 veces el salario medio de un trabajador y en al año 2000 cobra mil veces más. En los últimos 20 años la renta de Estados Unidos creció el $30 \%$, pero en las familias de clase media la renta sólo ha subido un $10 \% "$

${ }^{25}$ La Unión Europea (UE) compuesta por 25 Estados, hasta diciembre de 2006. La UE-15, a su vez, fue la existente entre ... de ... y diciembre de 2003.

${ }^{26}$ EDIS (Equipo de Investigación Sociológica) et al. (2000) Las condiciones de vida de la población pobre desde una perspectiva territorial. Pobreza y territoria Madrid, FoESSA. Los datos de esta investigación, ejemplo como siempre de rigor científico, han sido "oficializados" por el Consejo Económico y Social, que basa en ellos su informe de 2001; cfr. CONSEJo Económico y Social (2001) La pobreza y la exclusión social en España: propuestas de actuación en el marco del plan nacional para la inclusión social, Madrid, CES. 
El sistema actual no puede asegurar un empleo decente a todas las per sonas que concurren al mercado de trabajo. Como mucho, se nos promete todo tipo de ayudas para situarnos mejor en la competencia por el empleo, lo que es ya una manera de reconocer la imposibilidad estructural de que todas las personas accedan a un empleo con derechos. Pero al asociar ingresos y empleo está reduciendo en la práctica el derecho humano fundamental a llevar una vida digna, sin humillaciones, sólo a aquellas personas que pue den contar con un empleo que les reporte ingresos suficientes y estables. Hay que decirlo con toda claridad: la promesa universalista de que todas las personas alcanzaremos nuestro máximo desarrollo en la medida en que nos sometamos a las exigencias del mercado ha demostrado ser, al margen de la intención de sus promotores, una falacia.

La crisis de la sociedad salarial ha convertido en realidad cotidiana aquella que Hannah Arendt considerara la peor de las situaciones que cabría imagi nar: la perspectiva de una sociedad de trabajo sin trabajo. Los trabajadores sin trabajo, o con trabajo precario, se convierten así en ciudadanos sin ciudadanía, o en ciudadanos precarios.

\section{Un tiempo de biografías rotas}

Una mujer de 38 años, médico, trabaja desde hace nueve años como anes tesista interina en un gran hospital público de Madrid. Como tantas otras mujeres, había retrasado su maternidad a la espera de consolidar su puesto de trabajo porque, como ella misma señala, "estando de interina siempre tienes miedo a perder el trabajo por quedarte embarazada". Harta de esperar, finalmente decide tener su primer hijo. En efecto, queda embarazada y en su momento el ginecólogo la informa de que la fecha prevista para el parto era la del 26 de octubre. Pero hete aquí que la fecha probable para salir de cuentas venía a coincidir con la fecha propuesta por el Ministerio de Sanidad para convocar la primera Oferta de Empleo Público en casi quince años, cuya primera prueba se celebró el domingo día 27 de octubre. Podemos imaginarnos perfectamente la angustia de esa mujer perpleja e indefensa al ver cómo sus dos ilusiones, la maternidad y la consolidación de su empleo, entraban en conflicto. El decreto de oferta pública especial de empleo no contempla la posibilidad de habilitar nuevas convocatorias en otras fechas. ¿Qué hacer? ¿arriesgarse a no poder hacer el examen por coincidir éste con alguna de las fases del parto, perdiendo así tal vez toda posibilidad de acceder a un empleo estable? La solución: adelantar artificialmente el parto 
una quincena de días recurriendo a una cesárea. ${ }^{27}$ ¿Se trata de una simple anécdota? ¿Es tan sólo un caso extremo? Creo que no.

Tradicionalmente la actividad laboral ha servido para contribuir a dar coherencia a nuestras biografías. La historia de trabajo de la mayoría de las personas era, hasta no hace mucho tiempo, absolutamente lineal: aunque se cambiara de actividad, incluso aunque se cambiara de empresa, los logros eran siempre acumulativos. De hecho, todos los cambios se explicaban, precisamente, por lo hecho hasta ese momento. Con el paso del tiempo se iba ganando en experiencia y era esta experiencia ganada la que servía para construir una escala ascendente por la que el trabajador avanzaba a lo largo de su vida laboral. Por eso entrevistar a un trabajador mayor de 50 años e invitarle a contarnos su historia nos permite construir un relato coherente de su trayectoria profesional, a la manera de las grandes narraciones clásicas: con un comienzo, un desarrollo y un final claramente entrelazados. Hoy esto es algo que empieza a resultar imposible. Para la mayoría de los trabajadores actuales su historia laboral se asemeja más a un pequeño relato posmoder no, construido con pinceladas aparentemente inconexas: una sucesión de empleos nula o escasamente relacionados entre sí, de manera que no es fácil valorar si el cambio de empleo supone una mejora o no más allá de lo inmediato, ya que no es posible establecer un proyecto a largo plazo. Esto es algo especialmente evidente en el caso de los jóvenes.

Valgan, como ejemplo, algunas de las entrevistas mantenidas en el trans curso de una investigación dirigida por el autor. ${ }^{28}$ A pesar de la juventud del entrevistado, el relato de su recorrido por el mercado de trabajo dibuja una biografía laboral fragmentada, un relato espasmódico, en el que llama sobremanera la atención tanto la cantidad y variedad de actividades desa rrolladas, como la nula conexión entre estas:

Hice un curso ocupacional y después del curso ocupacional, que era de zapatería y de artículos de camping, pues hice prácticas de empresa [que] me sirvieron para coger un poco de experiencia, pero allí no hacían contratos ni nada, ni querían gente. Repartí currículums por todo el gremio de toldos y zapatería y no recibí respuesta. También eran años malos, era sobre el ochenta y algo, años malos que había poco trabajo. [...] Estuve vendiendo seguros y fui a la mili. Volví en verano y fui a trabajar [en la empresa donde] había hecho las prácticas de los toldos, pero sin contrato ni nada. Estuve tres meses y después comencé a trabajar en la Naval de Sestao. Le comentaron

27 El País, 21 de octubre de 2002.

28 I. Alonso de Armiño, I. Gómez, G. Moreno e I.Zubero (2002), "Precariedad laboral, precariedad vi tal”. Un amplio informe sobre la misma se ha publicado en la revista Inguruak, nº 32, 2002. 
a mi padre que necesitaban gente y estuve allí un año y pico, hasta que cerraron los diques de reparación. Luego estuve una temporada yendo a Santander. [...] Y luego estuve en Erandio haciendo cabinas de pintura... en unas condiciones que hoy en día no las aceptaría de ninguna forma. Lo único que bueno, tenía dinero, vivía en casa de mis padres y con ese dinero me valía. [...] Allí estuve tres años, me echaron a mí y a otros quince compañeros porque era la manera de no hacer fijos, nos fueron echando a plazos, metiendo gente para que aprendiese el trabajo... Ese mismo año fue el año que yo había comprado el piso. [...] Estuve echando solicitudes, haciendo entrevistas para cursos del paro, de Langai, por todos sitios. Y no hubo forma de hacer ningún cursillo. En unos estaba muy formado, en otros no tenía la formación necesaria y en otros había mucha gente. [...] Comencé a trabajar de nuevo en un par de cosas. [...] Estuve en montaje de estructuras un año o así, pero tuve que dejarlo porque empecé a sufrir de vértigo. [...] Tuve un par de experiencias con ETT bastante malas y decidí que había que buscar la forma de hacer algún curso. Hice un curso [de máquina-herramienta] en el cual nos aseguraban un 70 por ciento la colocación, aseguradas las prácticas y tal. [...] Las prácticas se cayeron abajo, en un sitio decían que era muy mayor para hacer prácticas y en otro sitio lo que querían era un tío para darle a un botón a una máquina ocho horas y no pagarle un duro durante tres meses. [...] Luego me saqué el FP I de auxiliar técnico ajustador, al año siguiente me saqué el de auxiliar técnico forestal. [...] Ahora me he apuntado a un grado medio a distancia... Y ahora mismo trabajo equipando furgonetas, tanto para camping, oficina, lo que sea... (E 23: Fidel, que tiene 28 años en el momento de la entrevista; su piso está expropiado).

El que acabamos de recoger es sólo un ejemplo especialmente significa tivo, pero no es excepcional. Son minoría aquellos que pueden relatar una trayectoria laboral dotada de una mínima coherencia. La biografía laboral de casi todos presenta la misma dislocación. Así, Patxi (E 20), tras finalizar sus estudios de Económicas, ha sido camarero en una cervecería, comercial de una empresa dedicada al reciclaje de cartuchos de impresora, aprendiz en una empresa de tubos de aluminio o comercial en una editorial de libros de texto. Olga (E 26), licenciada en Geología, ha trabajado como encuestadora y teleoperadora para varias empresas, a la vez que continuaba estudiando gemología. Imanol (E 13) ha estudiado Ciencias Políticas y ha trabajado como cuidador de autobús escolar, cuidador de comedor, entrenador de futbito, camarero en un bar, conductor de una camioneta de transporte de trabajadores, a la vez que prepara una oposición para la administración vasca. Jorge (E 9) está finalizando la carrera de Geografía y ha trabajado como socorrista, repartidor de colonias, cargando y descargando cajas o como auxiliar en una oficina. Jon (E 3), que ha terminado FP I de electrónica y se encuentra cursando un módulo de grado medio, caracteriza su expe riencia laboral como una sucesión de "cosillas sueltas [...] desde descargar camiones, seguridad en conciertos, buzoneos, en un videoclub, así, cosas varias, con contrato sólo en el videoclub". En el momento de la entrevista se encontraba trabajando como encuestador para el Censo de Población. Juan 
(E 19), que ha estudiado FP II y Educación Social, nos presenta igualmente un inacabable listado de las más variadas ocupaciones:

He trabajado en muchas cosas, desde echar propaganda, sin contrato ni nada, hasta, bueno, he estado de auxiliar sanitario en una residencia de ancianos durante nueve meses, durante año y medio de pica en Euskotren, luego también he estado seis meses en una tienda de ropa, he hecho labores administrativas en algunas empresas en sustituciones en vacaciones y luego ya pues pequeñas cosas, dar clases y cosas que van saliendo así, por una ETT currar un día en una fundición, cosas así.

Son pocos los empleos en los que existe un sistema normalizado de progresión mediante la acumulación de experiencia y de méritos profesionales, lo que permite hacer inversiones de futuro postergando la gratificación por el trabajo realizado en cada momento. En la mayoría de los empleos, la fragmentación, la discontinuidad y la incertidumbre son las que dominan. Y con ellas irrumpe en la vida del trabajador la más profunda y persistente incomodidad, perturbando gravemente su actividad y, lo que es peor, su vida misma.

Para la mayoría de los trabajadores actuales su historia laboral se asemeja más a un pequeño relato posmoderno, construido con pinceladas aparente mente inconexas: una sucesión de empleos nula o escasamente relacionados entre sí, de manera que no es fácil valorar si el cambio de empleo supone una mejora o no más allá de lo inmediato, ya que no es posible establecer un proyecto a largo plazo. Esto es algo que afecta, especialmente, a los jóvenes. Se genera así una situación døpobreza encubierta, que no aflora exclusivamente porque muchas personas se ven obligadas a mantenerse en una posición de inserción limitada: hay personas, muchas, que si en el momento actual no son consideradas pobres es, sencillamente, porque están postergando decisiones tan fundamentales como la de independizarse de sus hogares familiares, emparejarse o tener hijos; si tomaran alguna de estas decisiones, caerían inevitablemente por debajo del umbral de la pobreza.

Y es que, ¿cómo es posible ser pobre cuando se está creando tanto empleo? Se extiende así la idea del pobre como víctima, sí, pero víctima de sí mismo (de sus adicciones, de su amoralidad, de su estulticia) o de sus circunstancias (de su entorno familiar, de su fracaso escolar). La falta de trabajo y de dinero no es la causa, sino la consecuencia del modo de vida de esta nueva clase de marginados.

Es bien conocida la distinción realizada por Robert Castel entre tres zonas de organización o de cohesión social: una zona de integración, que configura lo que podíamos denominar la sociedad "normal"; una zona de 
vulnerabilidad, caracterizada por la precariedad del trabajo y la fragilidad de los soportes relacionales; y unazona de exclusión, de gran marginalidad, de desafiliación. ${ }^{29}$ La zona de vulnerabilidad ocupa una posición estratégica, una frontera porosa, fácilmente transitable, menos una tranquilizadora barrera defensiva que un recuerdo permanente del destino posible de la mayoría de las personas: la caída en el agujero negro de la exclusión.

\section{CUADRO 1}

\begin{tabular}{|c|c|c|}
\hline $\begin{array}{c}\text { ZONA DE } \\
\text { INTEGRACIÓN }\end{array}$ & $\begin{array}{c}\text { ZONA DE } \\
\text { VULNERABILIDAD }\end{array}$ & $\begin{array}{c}\text { ZONA DE } \\
\text { EXCLUSIÓN }\end{array}$ \\
\hline empleo estable & empleo precario & expulsión del empleo \\
\hline $\begin{array}{c}\text { inserción relacional } \\
\text { fuerte }\end{array}$ & fragilidad relacional & aislamiento social \\
\hline
\end{tabular}

Elaboración propia, a partir de R. CASTEL, op. cit.

¿Cómo se desencadena el proceso de exclusión social? Aunque la variable "empleo" es determinante, no es la única. Castel construye su propuesta de zonificación social trabajando dos variables que son, por un lado, la función integradora del trabajo y, por otro, la densidad de la inscripción relacional en redes familiares y de sociabilidad.

En opinión de Castel una característica importante de la coyuntura ac tual es la ascensión de la vulnerabilidad, el ensanchamiento de esa zona de frontera entre la integración y la exclusión, provocado fundamentalmente por la precarización del trabajo. Esta situación influye, por un lado, en la inestabilización de determinadas categorías sociales, como los jóvenes, pero también en la desestabilización de los estables, ante la entrada en una situación de precariedad de una parte de aquellos que habían estado per fectamente integrados en el orden del trabajo. Esta representación en tres espacios puede, si no somos muy cuidadosos, volver a retrotraernos a un

29 R. CASTEl (1995), "De la exclusión como estado a la vulnerabilidad como proceso", en Archipiélago, $\mathrm{n}^{\mathrm{o}}$ 21. Esta distinción de tres espacios fue revisada en su conocido trabajo, cfr. $\mathrm{R}$. CASTEl (1997), La metamorfosis de la cuestión social [ed. orig. 1995], Barcelona, Paidós, p. 418), incluyendo una cuarta zona, denominada "zona de asistencia", situada entre la vulne rabilidad y la exclusión. 
imaginario caracterizado por la estabilidad, a una visión nuevamente estática del fenómeno de la exclusión.

Por eso, resulta fundamental recordar que entre esas tres zonas o ámbitos sociales existen territorios compartidos, fronteras porosas que hacen que el paso de un espacio al otro no sea, al menos en sus inicios, tanto una ruptura como una transición.

GRÁFICO 1

Dinámicas de Exclusión

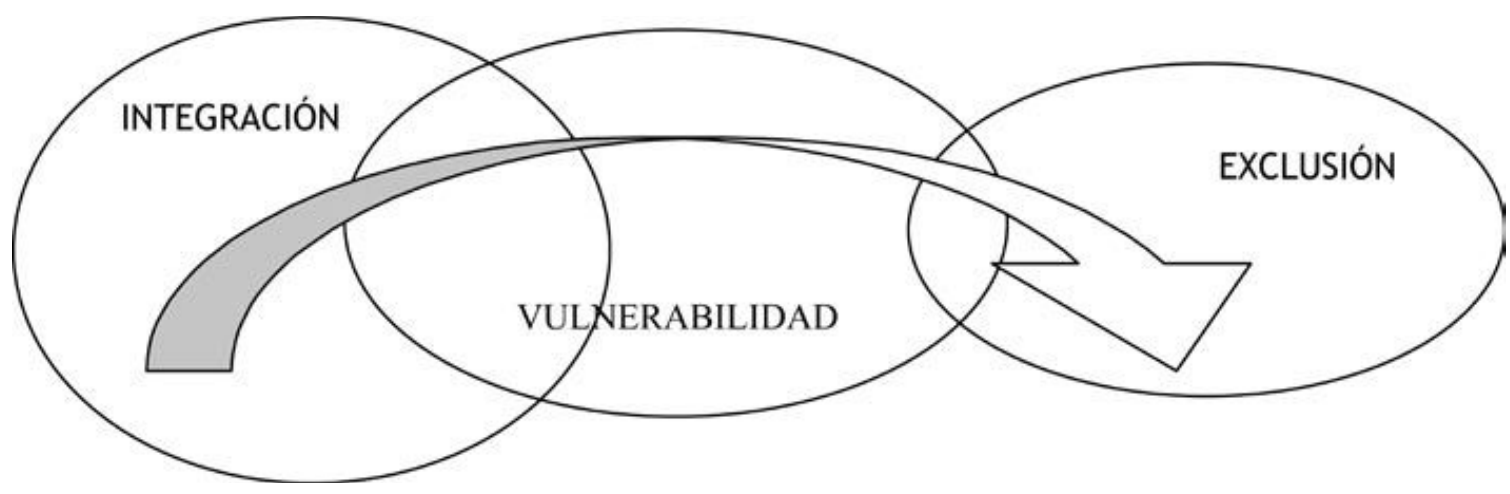

Elaboración propia

En efecto, como señala Castel, lo habitual suele ser que las dinámicas de exclusión estén actuando antes de que la persona en cuestión llegue a encontrarse en situación de exclusión. De ahí su acertada propuesta de intervención:

El tratamiento social de la exclusión no puede ser únicamente el tratamiento de los excluidos. La exclusión es lo que se encuentra al final de una cadena, es lo que nos encontramos, y nos encontraremos cada vez más, en la exacta medida en que se renuncie a actuar río arriba, en sus fuentes.

La característica más definitoria de la coyuntura actual esdacensión de la vulnerabilidad, el ensanchamiento de la zona de frontera entre la integración y la exclusión, que deriva fundamentalmente de la precarización del trabajo. Esta situación provoca, por un lado, la inestabilización de determinadas categorías sociales, como los jóvenes y las mujeres, pero también la desestabilización de los estables, ante la entrada en una situación de precariedad de una parte de aquellos que habían estado perfectamente integrados en el orden del trabajo y que ahora se ven excluidos de los derechos de ciudadanía 
asociados al estatus de trabajador a tiempo completo. Nos encontramos, por tanto, no únicamente ante la precarización de la relación de trabajo sino también

ante la desestructuración de los ciclos de vida normalmente secuenciados por la suce sión de los tiempos de aprendizaje, de los tiempos de actividad y del tiempo ganado y asegurado por la jubilación, una desestructuración marcada por todos los riesgos de desestabilización que esto supone para los modos de vida y las redes relacionales. En otros términos lo que se ve así amenazada ya no es únicamente la integración por el trabajo sino también la inserción social al margen del trabajo (Castel).

\title{
6. La globalización como disculpa
}

¿Quién fue el asesino del pacto social de posguerra? "La mundializaciớa hecho del "ajuste» un fenómeno universal para los países ricos y los pobres por igual", dice el Director General de la OIT. Es éste un lenguaje que se acerca peligrosamente al naturalismo con que la OCDE se aproxima a las realidades socioeconómicas. Ejemplo memorable de este naturalismo es el estudio de 1994 de la OCDE al que ya nos hemos referido, que empezaba así:

\begin{abstract}
El paro estructural aparece cuando existe un desfase entre las presiones a las que las economías se ven sometidas para adaptarse al cambio y la capacidad de estas últimas para responder. La adaptación es esencial para progresar en un mundo que se caracteriza por la multiplicación de nuevas tecnologías, la globalización y la dura competencia que se ejerce a nivel nacional e internacional.
\end{abstract}

El paro estructuralaparece..., advertía hace una docena de años la OCDE; la mundialización ha hecho..., lamenta ahora la OIT. En ambos casos, fenómenos de apariencia cuasinatural, ajenos a cualquier voluntad humana, provocan situaciones de riesgo o de amenaza democráticas al afectar "a todas las categorías sociales", a "los ricos y los pobres por igual". Ya he sometido a crítica en otro lugar esta pretensión de naturalizar lo que no son, en cualquier caso, otra cosa que procesos sociales. ${ }^{30}$

El uso de un lenguaje tan determinista que alimenta una visión naturalista de la realidad. Lejos de esta perspectiva naturalista, lo cierto es que, "los mercados con limitaciones son la norma en toda sociedad, mientras que los libres mercados son producto del artificio, de la estrategia y de la coerción política" ${ }^{31}$ Hace falta mucha estrategia política y mucha intervención estatal

30 I. ZuBero (2000), El derecho a vivir con dignidad: del pleno empleo al empleo pleno, Madrid, HOAC.

31 J. Gray (2000), Falso amanecer, Barcelona, Paidós. 
para producir y sostener un mercado liberado de las constricciones de la política; por ello sentencia Heilbroner:

Eliminemos el régimen del capital - y el Estado seguirá existiendo, aunque pueda cambiar de un modo impresionante; eliminemos el Estado y el régimen del capital no durará un solo día. ${ }^{32}$

En cualquier caso, ¿cómo y por qué se produjo el actual divorcio entre capitalismo y régimen de bienestar? Hoy recordamos -con una nostalgia que contribuye a velar algunos de sus aspectos menos luminosos- un capitalismo del bienestar como un orden social tan fructífero "porque logró unir la ciudadanía social, el pleno empleo, la educación masiva y unos sistemas de relaciones industriales que funcionaban bien".33

El reconocido académico e investigador David Harvey ha propuesto en una de sus últimas obras una interpretación del proceso que dio al traste con el compromiso de clase sobre el que se alzaron las distintas experiencias de capitalismo del bienestar desarrolladas no sólo en Europa, sino también en Japón e incluso en Estados Unidos, y cuyo paradigma fue el modelo es candinavo: el periodo que se inicia desde finales de los años 70, que hemos denominado como neoliberalismo, ha sido fundamentalmente un proyecto destinado a restaurar el poder de la clase capitalista. ${ }^{34}$

Desde el principio, política y mercado se mostraron como dos ámbitos o esferas sociales guiadas por lógicas distintas, en absoluto fáciles de armo nizar. Lo que había nacido para evolucionar unido (un individuo moderno que, como ciudadano y como trabajador, vive autónomamente) funcionó así sólo durante las tres décadas que siguen a la segunda guerra mundial, y lo hizo exclusivamente gracias a una coyuntura económica (crecimiento permanente) y política (pacto entre capital y trabajo tutelado por el Estado) muy concreta.

32 R. L. Hellbroner (1990), Naturaleza y lógica del capitalismo, Barcelona, Península.

33 G. EsPING-ANDERSEN (2000), Fundamentos sociales de las economás postindustriales, Barcelona, Ariel.

34 D. HaRvey (2005), A Brief History of Neoliberalism, Nueva York, Oxford University Press. 
GRÁFICO 2

Cuatro fases históricas en la tensión entre mercado y política

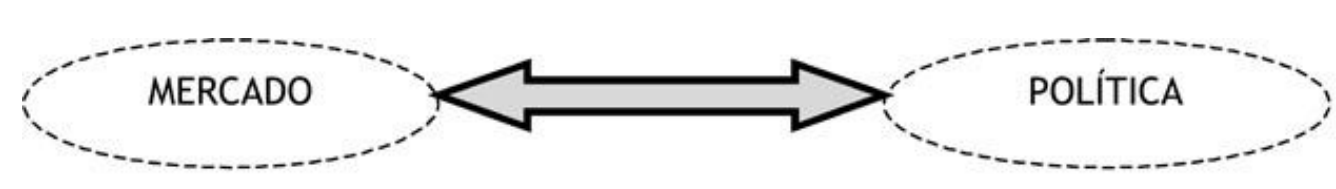

$\underline{1^{a} \text { fase: }}$ Orígenes del capitalismo, Revolución Industrial

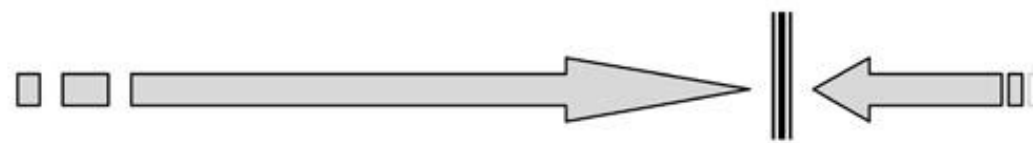

$2^{\mathrm{a}}$ fase: Último cuarto del siglo XIX. Hasta la I Guerra Mundial y período de entreguerras

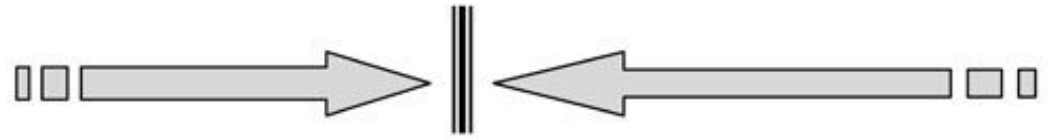

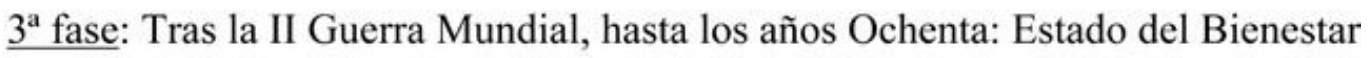

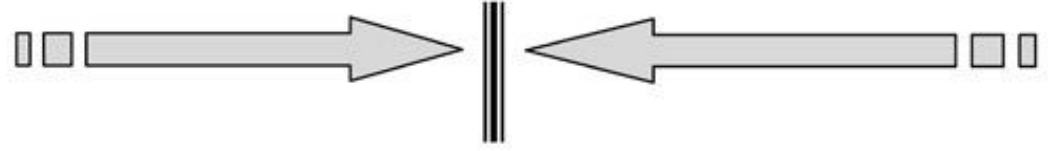

$\underline{4^{\mathrm{a}} \text { fase: }}$ Desde los Ochenta hasta la actualidad: Globalitarismo

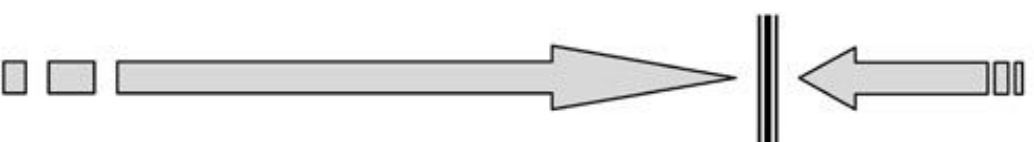

Elaboración propia

A partir de los 80, con el objetivo de "liberar la acumulación de todas las trabas que le impuso la democracia" (Przeworski), hizo naufragar el proyecto histórico de la ciudadanía moderna: 
El período actual, sin embargo, es el primero desde los años veinte en que los pro pietarios del capital han rechazado abiertamente un compromiso que implique la influencia pública sobre las inversiones y la redistribución de la renta. Por primera vez desde hace varias décadas, la derecha tiene su propio proyecto histórico: liberar la acumulación de todas las trabas que le impuso la democracia. Porque la burguesía nunca terminó su revolución.

En cuanto liberó la acumulación de las restricciones del feudalismo, la burguesía se vio obligada a sujetarla al control popular ejercido a través del sufragio universal. La combinación de la propiedad privada de los medios de producción y el sufragio universal es un compromiso, compromiso que implica que la lógica de la acumulación no sea exclusivamente la lógica de unos actores privados.

Lo que implica la actual ofensiva de la derecha no es una simple cuestión de impuestos, de gasto público, o ni siquiera de redistribución de la renta. Los planes de mitigación de impuestos sobre beneficios, eliminación de los controles ambientales, eliminación de los controles gubernamentales sobre la seguridad del producto y sobre las condi ciones de trabajo, y debilitamiento de los sindicatos es más que una reorientación de la política económica. Constituyen un proyecto de nueva sociedad, de una revolución burguesa. ${ }^{35}$

Según el análisis de Colin Crouch, hoy vivimos en sistemas que denomina posdemocracias. Por supuesto existen elecciones periódicas como conse cuencia de las cuales se producen cambios en los gobiernos, pero en estas sociedades la participación ciudadana y el debate público se reduce cada vez más a un estrecho abanico de temas, estando tanto la agenda política como, sobre todo, la gestión política, controladas por un reducido colectivo de políticos profesionales y de sus equipos de asesores. En el contexto de una posdemocracia, el poder de los grupos de presión empresariales, en particular el de las empresas globales, es cada vez más importante.

También Jean-Paul Fitoussi reflexiona sobre lo que denomina eretroceso "pacífico" de la democraciacomo consecuencia de la creciente presión a que se ven sometidos los regímenes democráticos por parte de las exigencias del capitalismo global:

La tutela de los mercados, el endurecimiento de la coerción que se impone a los go biernos nacionales, la reducción de sus pretensiones redistributivas, son otros tantos elementos que vienen a modificar el sistema equitativo de nuestras sociedades, por un retorno a los principios teóricos y por una desaparición progresiva del terreno democrático.

En opinión de Crouch, una causa fundamental del declive democrático en la política contemporánea es "el importante desequilibrio que actualmente

35 A. Przeworski (1988), Capitalismo y socialdemocracia, Madrid, Alianza. 
se produce entre los intereses empresariales y los de prácticamente todo el resto de los grupos".

Lo que casi nunca aparece en los numerosos estudios o noticias sobre la globalización es lo más relevante: la generación de unas posibilidades, casi ilimitadas, para el ejercicio de la desresponsabilización, nueva fuente de poder.

Aunque las características clásicas del poder siguen vigentes, en la acturali dad emerge una nueva forma de poder, basado menos en la capacidad de $\epsilon$ on trolar básicamente espacios y personas que en la capacidad de emanciparse de cualquier control desresponsabilizándose de la gestión de los espacios y las sociedades; éste es un poder que reside menos en la capacidad de obligar que en la de no sentirse obligado. Ambas formas de poder, la tradicional y la nueva, mantienen relaciones ambiguas, reforzándose en algunos casos, enfrentándose en otros. Ésta nueva cualidad del poder está perfectamente descrita en el siguiente texto del sociólogo Zygmunt Bauman:

En el mundo de hoy, la movilidad se ha convertido en el factor estratificador más po deroso y ambicionado, la materia de la que se hacen y rehacen cada día las jerarquías sociales, políticas, económicas y culturales. La movilidad adquirida por los propietarios y administradores del capital significa un nuevo -y en realidad sin precedentes por su radical incondicionalidad-descompromiso del poder respecto de toda obligación: de los deberes para con los empleados, pero también para con los más jóvenes y los más débiles, o incluso con las generaciones aún no nacidas y la autorreproducción de las condiciones de vida de todos; en suma, libertad de la obligación de contribuir a la vida cotidiana y la perpetuación de la comunidad. Hay una nueva asimetría que aparece entre la naturaleza extraterritorial del poder y la territorialidad de la «vida entera", que los poderes ahora sin amarras, capaces de trasladarse sin previo aviso o casi, son libres de explotar y abandonar a las consecuencias de esa explotación. Sacudirse la responsabilidad por las consecuencias es el beneficio más ambicionado y apreciado que la nueva movilidad aporta al capital que flota libremente y carece de vínculos locales. ${ }^{36}$

¿Cuál es la naturaleza del poder que ofrece la movilidad? La desresponsa bilización. "Quien tenga libertad para escapar de la localidad, la tiene para huir de las consecuencias". ${ }^{37}$ De esta manera, queda patente el contraste entre "la extraterritorialidad de la nueva elite con la territorialidad forzada del resto". 38

36 Z. Bauman (2001), La sociedad individualizada, Madrid, Cátedra.

37 Z. Bauman (1999), La globalización. Consecuencias humanas, Buenos Aires, Fondo de Cultura Económica.

38 Ibid. 


\section{La secesión de los triunfadores}

En efecto, el triunfo de la explicación neoliberal del funcionamiento económico ha coincido con el éxito de una revolución conservadora. Por su parte, Therborn sostiene que "la dinámica económica del capitalismo actual aparece acompañada por una reorganización político-social conservadora, como una revancha contra los avances culturales, políticos y sindicales de la izquierda en los años sesenta y setenta ${ }^{39}$. No se trata tanto de una derrota electoral de las fuerzas de izquierda, cuanto de unriunfo cultural de la visön conservadora de la realidad. La principal consecuencia de este triunfo ha sido una profunda relectura de nuestra historia reciente que ha despreciado radicalmente la aportación de la solidaridad y la seguridad colectiva al éxito económico y social de occidente:

Es como si, en algún momento alrededor de 1980, los hijos de la gente que se abrió paso durante la gran depresión hasta llegar a los barrios residenciales, hubieran decidido demoler ese puente después de haberlo cruzado. Decidieron que, aunque la movilidad social había sido apropiada para la generación de sus padres, ya no se le consentiría a la próxima generación. ${ }^{40}$

Resulta sorprendente la rapidez con la que olvidamos nuestra propia his toria, nuestra filiación. ¡ Con qué facilidad olvidamos que lo que hoy somos es consecuencia de una historia de solidaridad! Los que hemos triunfado en los años 60, 70 y 80 -los que tenemos formación, buenos empleos, seguridad social, etc.- somos el mejor ejemplo del valor de la solidaridad. Somos hijos e hijas del Estado de bienestar. Pero ahora que hemos triunfado nos sentimos amenazados por aquellas personas que tan sólo piden las mismas oportu nidades que nosotros tuvimos, y nos olvidamos de todo aquello que nos permitió llegar hasta donde hoy estamos: becas para estudiar, seguridad en el empleo, salarios dignos, etc. Nos aferramos a un falso discurso individua lista, reconstruimos una falsa historia de méritos personales y exigimos a los demás que se ganen la vida por sus propios medios. ¡Qué pronto olvidamos que una vez fuimos frágiles y que si logramos salir adelante fue gracias a la solidaridad de los demás!

Este es el problema. Se ha producido una "secesión de los triunfado res" (Reich) y estos han logrado construir un "horizonte de expectativas"

39 G. Therborn (1993), "El futuro del trabajo y las consecuencias de la ausencia de trabajo": El Socialismo del Futuro, nำ 7 .

40 R. RoRty (1999), Forjar nuestro país. El pensamiento de izquierdas en los Estados Unidos del siglo XX, Barcelona, Paidós. 
(Bourdieu), un discurso dominante que sirve para constituye una auténtica teodicea (o sociodicea) de los privilegiados, dirigida a naturalizar su situación de privilegio en medio de un mundo cada vez más amenazado por la inseguridad y el riesgo.

Este discurso se funda en la idea dæesponsabilidad internalizada, ${ }^{41}$ según las cual cada individuo es responsable de su propio bienestar y las políticas públicas deben orientarse fundamentalmente a "ayudar a quien se ayuda". Como denuncia irónicamente Krugman:

Por supuesto, ahora vivimos en los que George W. Bush llamó la «época de la responsabi lidad individual»: si un niño elige tener unos padres que no pueden permitirse la atención sanitaria, ese niño habrá de enfrentarse a las consecuencias de su elección. ${ }^{42}$

Desde esta perspectiva, el modelo europeo de welfare se desliza hacia el workfare estadounidense y la intervención pública es sometida a la más áspera de las críticas:

Las regulaciones son el caldo de cultivo de la irresponsabilidad: se trata de trabajar menos, de cobrar pensiones sin haber ahorrado, de subvencionar todo, es decir, de impedir que sepamos y sintamos lo que cuestan las cosas, y que seamos responsables de nuestro destino. ${ }^{43}$

Se reivindica el mercado como la mejor "política social" y se reconduce la iniciativa ciudadana al terreno de la ayuda caritativa, al terreno de la virtud individual, pero se rechaza cualquier institucionalización pública de la soli daridad. Los pobres ya no son simplemente pobres, ya no son desempleados; son inempleables: carecen de las habilidades necesarias para satisfacer una demanda de nuevos empleos cada vez más cambiante como consecuencia del cambio tecnológico y la globalización. Quien no "encuentra” empleo habrá de autoevaluar sus posibilidades, descubrir sus carencias y esforzarse por desarrollar sus habilidades. Hay empleo, pero hace falta saber encontrarlo. En todo caso, si no encuentra empleo él es el problema.

Según esto, el problema no es tanto de empleo cuanto de empleabilidad. ¿Qué hay que entender por empleabilidad? Sencillamente, la adecuación más perfecta posible a las condiciones que en cada momento existen en el mercado de trabajo. Se está suponiendo que quien no encuentra empleo es

41 D. Schmidtz (2000), “Asumir la responsabilidad”, en DSchmidtz y R. E.Goodin (2000)El bienestar social y la responsabilidad individual, Madrid, Cambridge University Press, p. 28.

42 P. Krugman (2004), El gran engaño, Barcelona, Crítica, p. 207.

43 C. Rodríguez Braun (2000), Estado contra mercado, Madrid, Taurus, p. 94. 
porque no cumple con esas condiciones; el problema está en el desempleado, al que más bien habría que denominar, desde esta perspectiva, "inempleable", no en el mercado de trabajo.

Vale más una imagen que mil palabras. El 20 de octubre de 2002, en su suplemento "Expansión \& Empleo", el diario El Mundo publicaba a página completa el anuncio de la celebración, en la Universidad Carlos III de Madrid, del VII Foro Nacional del Primer EmpleoF(OREMPLEO), dirigido a universitarios y recién titulados. El anuncio no podía ser más explícito:

¿Vas a seguir pasando los lunes al sol? Será porque quieras, porque en Forempleo no es difícil encontrar trabajo.

Así pues, se trata de incentivar la búsqueda de empleo: ¿de qué empleo? Se da por supuesto que del empleo que, en cada momento, sea ofrecido según las condiciones impuestas por las cambiantes necesidades del mercado.

\section{8. ¿Una vuelta a las condiciones sociales del antiguo régimen?}

Si hoy en día pensamos en cuáles son las variables que mejor pueden explicar las probabilidades de que se disfrute de una inserción laboral con éxito, junto a las muchas que intervienen, que influyen, pero no modifican la relación de causalidad, encontraremos dos variables independientes fun damentales: a) año de nacimiento; b) inclusión en un entramado de redes familiares y sociales potente.

\section{GRÁFICO 3}

\section{Variables para explicar la inserción laboral}

\section{Variables independientes \\ Año de nacimiento Redes familiares/sociales}

Elaboración propia
Variable dependiente Inserción laboral
Variables intervinientes

Sexo, edad, formación 
¿Por qué doy importancia al año de nacimiento? Nada de lo que en estos momentos se dice sobre las vías para acceder al empleo puede aplicarse a las carreras laborales de quienes hemos nacido antes de 1965. Recordemos lo comentado antes a partir del texto de Geertz, o lo que señalaba en un interesante reportaje Luis Garrido:

Cuando yo, que nací en 1956, estudiaba, sólo el 10\% de los jóvenes, la inmensa mayo ría chicos, conseguía una licenciatura universitaria. Esta claro que ese 10\% copó los puestos de elite de esta generación, la del 68, que arrasó. Y que mis coetáneos vimos que estudiando en la Universidad se llegaba lejos y se lo transmitió a sus hijos. A partir de los ochenta, el porcentaje de estudiantes universitarios se multiplicó, sobrepasando el $30 \%$ y sumando a las mujeres, que se incorporaron de forma masiva. Se produjo un vuelco educativo tremendo, incomparable a cualquier otro país europeo. Y no ha habido puestos buenos para todos. Por mucho que queramos, no hay. Y se ha creado número indeterminado de jóvenes frustrados, con una larga trayectoria estudiantil, que no ha rendido, que no ha ganado lo suficiente... ${ }^{44}$

¿Y las redes? Refiriéndose al caso de los Estados Unidos, Paul Krugman denuncia la creciente consolidación en ese país de un fenómeno alarmante: "el regreso a la posición social heredada". ${ }^{45}$ Frente al mito ampliamente extendido de la movilidad social norteamericana (eso de que un humilde portero puede llegar a ser presidente de los Estados Unidos), resulta que ese país se caracteriza por tener una distribución de rentas más estática a lo largo de las generaciones, que ningún otro país desarrollado, y, por lo tanto, menos oportunidades para progresar.

Las fortunas conseguidas muchos años atrás, "a partir de la explotación o el robo de terceros" apuntilla Krugman, siguen siendo fundamentales para explicar una estructura social enormemente desigual. A la vez que la vía fundamental para la movilidad social ascendente -un buen sistema edu cativo de acceso universal- ha ido deteriorándose, las posibilidades para la transmisión de privilegios no han hecho más que reforzarse: mediante la derogación del impuesto de sucesiones, por ejemplo, o mediante redes de influencia, enchufe y cooptación que acaban por configurar auténticas castas económicas, políticas y hasta culturales, en las que los hijos afortu nados heredan la posición social de sus padres, más allá de toda prueba de capacidad o mérito. Como señala Krugman:

${ }^{44}$ L. Garrido es catedrático de Sociología de la UNED, cfr. AlmÉnez BARCA (2005), "La generación de los mil euros": El País, Suplemento Domingo, 23-X-2005, pp. 1-3.

45 P. Krugman (2004), El gran engaño, cit., pp. 203-205. 
Hace treinta años, el ejecutivo jefe de una gran compañía era un burócrata con un buen sueldo, pero no un rico auténtico. No podía legar a sus herederos ni su posición ni una gran fortuna. Los imperiales ejecutivos jefe de hoy, por el contrario, dejarán grandes herencias tras de sí y, además, a menudo también estân en situación de conseguirles a sus hijos algún empleo lucrativo.

De ahí la fina ironía con la que Krugman resume su planteamiento: "Estados Unidos es, como todos sabemos, la tierra de las oportunidades. El éxito de una persona depende de su propia capacidad y de su empuje, no de lo que fue su padre. No tiene más que preguntárselo a los hermanos Bush". En definitiva, "las tendencias políticas, sociales y económicas otorgarán a lo hijos de los que hoy son ricos una inmensa ventaja sobre los que han elegido mal a sus padres". Class matters, "la clase importa". Lo desvela un excelente trabajo de investigación impulsado en 2005 por The New York Times ${ }^{46}$ Como en los tiempos en los que la herencia constituía el hecho dominante en las vidas de las personas, las posiciones vuelven a ser posesiones. ${ }^{47}$

¿Qué queda, en estas circunstancias, del discurso igualitario, central en nuestras sociedades democráticas?

\section{La crisis de la cohesión social}

La paradoja de la exclusión es que una sociedad, que sólo puede entender se a sí misma como orden e integración, está generando sistemáticamente colectivos incapaces de seguir el ritmo trepidante que marca una competiti vidad cada día mayor. No olvidemos que, en la forma del empleo, el trabajo es la forma actual que adopta el contrato social que une al individuo y a la sociedad, preservando el proyecto de movilidad social característico de la moral burguesa. ¿Hasta dónde puede una sociedad soportar esta tensión entre la fuerza centrípeta de la integración y la centrífuga de la exclusión? El caso es que todo esto seguirá así "mientras no se acabe con esa idea de normalidad que cifra todo el valor y el éxito de la vida de las personas según se desenvuelvan en el mercado de trabajo y según como sea su vida laboral y profesional", como señala Offe, quien concluye esta reflexión diciendo:

Ahora bien-concluye-, la idea según la cual sólo debería tenerse acceso a los bienes y valores de la vida si previamente se ha sido capaz de colocar con éxito la propia

46 Correspondents of THE NEW York Times (2005), Class Matters, Nueva York, Henry Holt.

47 R. SEnnett (2006), The Culture of the New Capitalism, New Haven \& London, Yale University Press (edición española, La cultura del nuevo capitalismo, Barcelona 2006, Anagrama). 
fuerza de trabajo en el mercado, es moralmente muy poco plausible. Pues ¿por qué razón deberían enhebrarse todas las actividades útiles que los seres humanos son capaces de hacer a través del agujero de la aguja de un contrato laboral? O ¿por qué razón se supone que es justo reservar las posibilidades de consumo, la seguridad social y el reconocimiento social a aquellos que se han hecho valer en el mercado de trabajo ${ }^{48}$

Ésta es la cuestión. No hay ninguna posibilidad de justificar moralmente, al menos desde la ética que emana de la lógica democrática de los derechos humanos, que la única puerta de acceso a la seguridad, la estima y el bien estar sea el empleo, cuando esta puerta está cerrada con llave y no todo el mundo posee una para abrirla.

¿Hay que merecer el derecho a vivir?: ésta es la gran pregunta que hemos de hacernos como sociedad. No podemos olvidar que la ética del trabajo, que aún constituye el eje de las sociedades modernas, no fue concebida pen sando en el trabajo como obligación, sino en el trabajo como oportunidad para la autonomía, para la construcción del propio itinerario vital, para la inserción en un entramado de derechos y obligaciones, etc., aunque existía una contradicción desde el principio. Como desvela Gorz, el capitalismo ha asociado sistemáticamente, a través de una concepción reduccionista de trabajo, la necesidad de un ingreso suficiente y estable con la necesidad de medirse con otros y de ser útil para otros, ambas cosas son claramente distintas:

La necesidad imperiosa de un ingreso suficiente sirve de vehículo para hacer pasar de contrabando «la necesidad imperiosa de trabajar». La necesidad de actuar, de obrar, de ser apreciado sirve de vehículo para hacer pasar de contrabando la necesidad de ser pagado por lo que se hace. ${ }^{49}$

De este modo, ninguna actividad será considerada "trabajo" si no se realiza en función de un encargo pagado por otra persona, y no existirá ninguna posibilidad de obtener un ingreso suficiente y estable si no es como remu neración de un "trabajo" así concebido.

Como es sabido, el contrabandista es experto en la trasgresión de fronteras. El contrabandista se sirve de su capacidad para traspasar clandestinamente las fronteras, introduciendo en un territorio productos prohibidos o, cuando

48 C. Offe (1994), “¿Pleno empleo? Para la crítica de un problema mal planteado”Debats, nº 50, diciembre, p. 72.

49 A. G orz (1998), Miserias del presente, riqueza de lo posible, Buenos Aires, Paidós, p. 83 [en el primer tramo de la cita, la redonda es del autor]. 
menos, sin el correspondiente control de los mismos. La calificación de con trabandista que Gorz aplica al capitalismo en el texto anterior es totalmente adecuada. Mediante la asociación entre ingreso y empleo, el capitalismo ha transgredido una delicada frontera, la frontera de los derechos humanos, la frontera de la ciudadanía, y ha introducido en la esfera de los derechos, de la sociabilidad y del reconocimiento el mecanismo de la utilidad.

Evidentemente, esta situación introduce una ruptura en nuestra retórica sobre la ciudadanía moderna y los derechos humanos, una profunda ruptura en el contrato social moderno. Vivianne Forrester ha expuesto con enérgica indignación sus consecuencias:

En este sistema sobrenada una pregunta esencial, jamás formulada: “ ¿Es necesario 'merecer' el derecho de vivir?" Una ínfima minoría, provista de poderes excepcionales, propiedades y derechos considerados naturales, posee de oficio ese derecho. En cambio el resto de la humanidad, para "merecer" el derecho de vivir, debe demostrar que es "útil" para la sociedad, es decir, para aquello que la rige y la domina: la economía aparece confundida más que nunca con los negocios, la economía de mercado. Para ésta, "útil” significa casi siempre "rentable”, es decir, que dé ganancias a las ganancias, en una palabra, significa "empleable" ("explotable" sería de mal gusto). Este mérito -mejor dicho, este derecho a la vida-pasa por el deber de trabajar, de estar empleado, que a partir de entonces se vuelve un derecho imprescriptible sin el cual el sistema social sería una vasta empresa de asesinato. ¿Pero qué sucede con el derecho de vivir cuando éste ya no funciona, cuando se prohíbe cumplir con el deber que da acceso al derecho, cuando se vuelve imposible cumplir con la obligación? ${ }^{50}$

El sistema actual no puede asegurar un empleo decente a todas las per sonas que concurren al mercado de trabajo. Como mucho, se nos promete todo tipo de ayudas para situarnos mejor en la competencia por el empleo, lo que es ya una manera de reconocer la imposibilidad estructural de que todas las personas accedan a un empleo con derechos. Pero al asociar ingresos y empleo el sistema está reduciendo en la práctica el derecho humano funda mental a llevar una vida digna, sin humillaciones, sólo a aquellas personas que pueden contar con un empleo que les reporte ingresos suficientes y estables. Hay que decirlo con toda claridad: la promesa universalista de que todas las personas alcanzaremos nuestro máximo desarrollo en la medida en que nos sometamos a las exigencias del mercado ha demostrado ser, al margen de la intención de sus promotores, una falacia.

50 V. ForRester (1997), El horror económico, México, Fondo de Cultura Económica, pp. 15-16 [la redonda de la última línea es de la autora]. 


\section{0. ¿Qué hacer?}

Vivimos una realidad que se caracteriza por el incremento de las situaciones de vulnerabilidad personal y social. La política social tradicional era paliativa y fue pensada para responder a necesidades extraordinarias y circunscritas a sectores concretos de la población; en estas condiciones actuales esa política muestra toda su fragilidad. Lo que necesitamos es una nueva red preventiva universal, apropiada a unos tiempos de flexibilidad económica, de manera que esta flexibilidad no suponga precariedad vital. Una política social para el futuro debe ser capaz de asumir y responder a la quiebra de la norma social de empleo y a la correspondiente aparición de cada vez más situaciones de precariedad laboral y vital; debe ser, por tanto, una política integral, a la altura de los retos estructurales que hoy tiene planteados nuestra sociedad; y debe ser, también, una política sostenible, que integre el reto de conciliar el bienestar en nuestra sociedad con la solidaridad internacional y el respeto al medio ambiente.

\subsection{Ampliar el concepto de trabajo}

Sin duda nos hallamos ante un asunto cuya importancia radica en que sus raíces se hallan en la línea de fractura del modelo económico y social hasta el momento vigente. El desempleo sólo encontrará solución utilizando un modo de pensar distinto del que es dominante en el sistema actual. Lo mismo cabe decir del conjunto de problemáticas asociadas a la transformación de la norma social del empleo: seguridad social, exclusión, cohesión social, etc. Estamos ante un problema que implica unaliscontinuidad, una ruptura, en la evolución de nuestra sociedad. En la medida en que estamos ante una situra ción totalmente nueva, las soluciones tradicionales, producto de un modo de pensar tradicional, van a mostrarse del todo inadecuadas para facilitar una respuesta satisfactoria a los intereses sociales en juego.

En su estudio sobre los fundamentos sociales de las economías postin dustriales, Esping-Andersen considera que el caballo de Troya que se ha infiltrado en los sistemas de bienestar europeos está constituido por la tríada siguiente:

El envejecimiento de la población, unas familias inestables y una grave disyuntiva entre bienestar y puestos de trabajo, igualdad y pleno empleo. ${ }^{51}$

51 G. EsPing-ANDERSEN (2000), Fundamentos sociales de las economías postindustrialeş Barcelona, Ariel. 
Mercado de trabajo, Estado de bienestar y familia deben ser, en su opinión, las tres patas sobre las que han de asentarse, también en el futuro, las socie dades democráticas, y, para ello, es preciso encontrar la manera de crear las condiciones sociales, económicas y políticas que permitan la optimización de cada una de esas esferas, teniendo en cuenta que:

a) El mercado de trabajo aspira a una mayor flexibilidad.

b) El Estado de bienestar precisa reforzar su base impositiva, para lo cual es preciso un nuevo régimen de fecundidad que compense el envejeci miento y un mayor número de personas con empleos bien remunerados, o, lo que es lo mismo, un menor número de personas dependientes de subsidios sociales.

c) Las familias necesitan, sobre todo, buenos empleos, buenos ingresos y buenos servicios públicos.

Si de verdad se va a hacer una apuesta por sistemas de producción flexi bles, como se plantea en el informe para la OCDE del mismo título al que ya nos hemos referido, es imprescindible poner las bases para unaflexibilidad sostenible. Esta es la única alternativa a la precarización de los empleos y de las vidas de cada vez más personas. Es urgente combatir todos aquellos procesos que transforman la flexibilidad del empleo en precariedad vital.

Para ello es preciso, en primer lugar, un gran acuerdo social a favor del derecho al trabajo con derechosque sólo será posible si repensamos nuestras ideas sobre el trabajo, en la línea planteada por diversas instituciones y ana listas. Desde esta perspectiva ampliada, podemos fijarnos en las siguientes propuestas:

— Liedtke y Giarini en su Informe al Club de Roma defienden un sistema de trabajo multiestratificado, de manera que se reconozcan tres estratos diferenciados de actividades productivas: el primero, un trabajo remu nerado equivalente a lo que puede ser el tiempo de trabajo básico, es decir, unas 20 horas semanales o unas 1.000 horas anuales, garantizado para todas las personas capaces mediante la intervención pública; el segundo, el trabajo remunerado desarrollado en condiciones de mercado; el tercero, las actividades de autoproducción, así como las voluntarias no remuneradas. ${ }^{52}$

52 O. Giarini y P. LiedtKe (1998), El dilema del empleo. El futuro del trabajo. Informe al Club de Roma, Barcelona, Galaxia Gutenberg - Círculo de Lectores. 
- Bouffartigue, en una línea parecida, ha propuesto la creación de un mecanismo de contratos de actividad, que liguen a cada persona a una red de empresarios privados o públicos, asociaciones y organismos de formación, de manera que cada individuo recibiría una renta en la me dida en que participe de las actividades de esa red, actividades que hoy pueden ser laborales, sociales mañana o formativas pasado mañan 53

- Carnoy y Castells, en el ámbito de la OCDE, han planteado algo similar para hacer frente al incremento delriesgo que amenaza a todos los tra bajadores en la nueva economía de la información y proponen organizar redes que configuren itinerarios en torno a la educación, la formación profesional y la información. ${ }^{54}$

- El Informe Supiot para la Unión Europea propone la definición de un estado profesional "que acompañara a las personas desde la cuna a la tumba, cubriendo tanto los períodos de inactividad propiamente dichos, como los períodos de formación, de empleo, de trabajo autónomo o de trabajo fuera del mercado". ${ }^{5}$

- Beck ha denominado la Europa del trabajo c ívico a una nueva Europa construida a partir del reconocimiento para todas las personas del "de recho al trabajo discontinuo que permita a las mujeres y a los hombres cambiar entre los distintos campos de actividad (trabajo convencional, trabajo doméstico, trabajo ćvico) según su propia discrecón", sin que tales cambios -añado yo- suponga merma alguna en las posibilidades de cada persona de llevar una vida digna. ${ }^{56}$

- Jordi Garcés ha hecho una propuesta sugerente: promover una forma de organización de servicios sociales a la que denomina Empresa Social Comprometida, cuyas características básicas serían: la eficiencia económica y social; un pequeño tamaño; una estructura que permita la cooperación en red, creando v ínculos territoriales amplios; y, por último, un apoyo en las raíces de la comunidad local. ${ }^{57}$

53 P. Bouffartigue (1999), "Francia: ¿la norma del empleo hecha trizas?”, en C.RIETo (ed.) (1999), La crisis del empleo en Europa, vol. 2, Alzira (Valencia) Germania.

54 M. Carnoy y M. Castells, op. cit.

55 A. Supiot (coord.) (1999), Trabajo y empleo, Valencia, Tirant lo Blanch.

${ }^{56}$ U. BECK, op. cit.

57 J. Garcés (2000), La nueva sostenibilidad social, Barcelona, Ariel. 
- Las organizaciones asentadas en valores comunitarios precisan de la discriminación positiva de las instituciones representantes de la sociedad para poder desarrollarse y desplegar en la sociedad los valores de cooperación y solidaridad, en retroceso en una cultura de valores acentuadamente competitivos, de búsqueda del éxito personal y cuyo resultado es una creciente desigualdad que est á carcomiendo las estructuras de nuestra sociedad.En el ámbito local hay numerosas necesidades sociales insatisfechas, lo que permite la realización de proyectos innovadores de inserción sociagenerando ocupación en torno a ellas. ${ }^{58}$

- Una propuesta a tomar en consideración es la instauración de los deno minados Créditos para el Ciudadano Activocon el objetivo de promover la ayuda mutua y proveer así una política complementaria de inclusión social. ${ }^{59}$ Nada de esto será posible sin un reforzamiento del espacio local.

\subsection{Garantizar la base económica de la ciudadanía}

El problema de las sociedades capitalistas estriba hoy, como siempre, en la poderosa tendencia del mercado a extender su lógica propia al conjunto de la sociedad invadiendo otras esferas, lo que ocurre de dos formas: redu ciendo toda realidad social a la categoría de "mercancía" e imponiendo como fundamento de la relación entre las personas y los grupos la capacidad de compra, en última instancia, el dinero.

El desarrollo del Estado del bienestar ha supuesto umbesmercantilización de los intereses de los trabajadores, al reemplazar la idea de "contrato" por la de "posición" y los "derechos de propiedad" por los "derechos de ciudadanía". ${ }^{60}$ Podemos hablar de desmercantilización porque las prestaciones sociales a las que el individuo tiene derecho no derivan de su posición real en las relaciones de mercado, sino que responden a una concepción social y

58 E. JimÉnez, F. BARReiro y J. E. SÁnchez (1999), Los nuevos yacimientos de empleo. Los retos de la creación de empleo desde el territorio, Barcelona, Icaria.

59 C. C. Williams y J.Windebank (2000), "Beyond social inclusion through employment: harnessing mutual aid as a complementary social inclusion policy": Policy and Politics, vol. 29, n. 1.

60 J. L. Monereo (1996), Derechos sociales de la ciudadanía y ordenamiento laboral, Madrid, CES, y C. Offe (1998), Partidos políticos y nuevos movimientos sociales, Madrid, Sistema. 
política en virtud de la cual se asume que los individuos o las familias pueden mantener un nivel de vida socialmente aceptable, independientemente de su participación en el mercado. En la actualidad, por el contrario, estamos asistiendo a una remercantilización de importantes sectores del espacio antes reservado a la previsión pública.

Pero en una sociedad como la nuestra, donde el acceso real a la ciudadanía pasa por la capacidad de disponer de unos recursos económicos suficientes y estables, la intrusión del cálculo económico y la eliminación de cualquier otra consideración social supone la aparición de una inaceptable dinámica de exclusión social. La combinación de paro persistente y de mayor liberałi zación de los mercados de trabajo alumbran un futuro poco esperanzador.

En el Informe al Club de Roma, que lleva por títuloFactor 4, podemos leer lo siguiente:

No se pueden esperar rápidos progresos [en el desarrollo de estilos de vida alternati vos] en un mundo en que tanto la base material de la vida como también el prestigio social están ligados de manera inseparable al puesto de trabajo y en que prácticamente todo se puede comprar con dinero. Debemos intentar separar en cierta medida la base material de la actividad profesional. La cuestión es crear o redescubrir una satisfacción equivalente y un prestigios social parecido al que existe en el campo profesional en trabajos dentro del ámbito doméstico y vecinal. Hay que redescubrir el valor propio -enterrado por la economía- del trabajo realizado en un contexto vecinal, doméstico o social. [Y se añade más adelante:] La base material de la vida y el prestigio social están ligados de manera prácticamente inseparable al puesto de trabajo. Este hecho es uno de los mecanismos más importantes que hacen que la política siempre se decida por los puestos de trabajo, sobre todo los industriales, en los momentos en que hay que tomar una decisión. [Pero] el bienestar y la prosperidad no están necesariamente vinculados al trabajo profesional. Las actuales ventajas del trabajo profesional, tales como la seguridad social y el reconocimiento de la sociedad, se podrían separar, al menos en parte, de este tipo de trabajo, mediante medidas graduales y sensatas" ${ }^{6} 1$

Los autores del informe Factor 4 apelan a la necesidad de reconocer el valor de actividades no mercantiles. Si lo pensamos bien, estas son las que realmente importan. No podemos vivir sin afecto, sin humor, sin poesía, sin solidaridad. Es preciso, por tanto, reconocer a las personas que son capaces de tales producciones no mercantiles, no por el valor mercantil de sus producciones, sino porque son producciones socialmente valiosas que sólo esas personas pueden hacer. Hay, pues, que valorarlas porque pueden hacerlas y para que puedan hacerlas, no porque las hagan. Así pues, aunque estamos

61 E. U. von Weizsäcker et al. (1997), Factor 4, Barcelona, Galaxia Gutenberg - Círculo de lectores [las redondas del texto sin corchetes son del original]. 
hablando de un reconocimiento que se concretatambién económicamente, no estamos hablando de un "salario" por hijo parido, por poema escrito, por canción cantada, por árbol plantado, o por anciano acompañado...

No es posible hacer depender los derechos asociados a la ciudadanía del funcionamiento libre del mercado. Hay que recuperar el contenido político de la ciudadanía. Y en la práctica, el ejercicio de la ciudadanía pasa por el acceso a los recursos necesarios para poder vivir con la mayor libertad posible. De ahí la reivindicación de disociar del empleo aquella renta básica considerada como mínimo vital para llevar una existencia digna. Ésta es la única forma de lograr que cualquier propuesta de generar empleo con dere chos tenga éxito: ya sea el reparto del empleo como el fomento del empleo a tiempo parcial, la flexibilidad, la polivalencia, la movilidad geográfica, el autoempleo o la formación continua, lo mismo que el trabajo fuera del mercado. Sin un ingreso suficiente y estable, garantizado como derecho de ciudadanía, al margen de nuestra relación con el mercado en cada momento, todas esas propuestas tendrán como consecuencia para muchas personas la precariedad vital. Lo considero, por tanto, como el eje irrenunciable de cualquier estrategia de lucha contra el paro y la degradación del trabajo o, más en general, de cualquier propuesta destinada a extender y fortalecer los derechos de ciudadanía. 